\title{
VALORIZAR E PRESERVAR O PATRIMÔNIO NATURAL EXPLORANDO AS ESPÉCIES INVASORAS
}

\author{
VALUING AND PRESERVING NATURAL HERITAGE \\ EXPLORING INVASIVE SPECIES
}

VALORIZAR Y PRESERVAR EL PATRIMONIO NATURAL
EXPLOTANDO LAS ESPECIES INVASORAS

Patrícia Alexandra Pessoa ${ }^{1}$

XANA SÁ-PINTO ${ }^{2}$

PEDRo CARdia3

Alexandre Pint 4

${ }^{1}$ Escola Superior de Educação do Instituto Politécnico do Porto. Portugal ${ }^{2}$ Politécnico do Porto- Escola Superior de Educação, Centro de Investigação em Didática e Tecnologia na Formação de Formadores. Portugal ${ }^{3}$ Politécnico do Porto- Escola Superior de Educação. Portugal ${ }^{4}$ Politécnico do Porto - Escola Superior de Educação. Portugal

Resumo A introdução de espécies exóticas representa uma grave ameaça à biodiversidade, apresentando-se as espécies exóticas invasoras como as que têm causado maior impacto nos ecossistemas. Assim, urge fomentar nos cidadãos a compreensão dos impactos da introdução dessas espécies na biodiversidade autóctone e no bem-estar das pessoas e desenvolver conhecimentos, atitudes e comportamentos que lhes permitam contribuir para minorar esse problema. Sendo esse um problema societal para cuja resolução a educação em ciências é fundamental, a sua exploração em sala de aula poderá contribuir para trabalhar diversos aspectos da literacia científica dos alunos numa abordagem de Ciência, Tecnologia e Sociedade. Contudo, escasseiam estudos sobre a capacidade dos alunos do primeiro ciclo compreenderem os impactos da introdução de espécies exóticas. Este trabalho avalia o impacto de uma sequência didática i) no reconhecimento do perigo da introdução de espécies exóticas e ii) na previsão do seu potencial invasor. Essa sequência didática foi aplicada em duas turmas do $3^{\circ}$. ano. Os resultados, avaliados por meio de pré e pós-testes, sugerem que essa sequência didática contribui para o reconhecimento dos perigos da introdução de espécies exóticas.

Palavras-chave: EducaÇão para a Ciência; Biodiversidade; Espécies Exóticas e InvasoRAS; Atividades Didáticas. 
Abstract The introduction of exotic species represent a serious threat to biodiversity, these species have caused the greatest impact on ecosystems. Therefore, is important to encourage citizens to understand the impacts of the introduction of these species on indigenous biodiversity and people's well-being and to develop knowledge, attitudes, and behavior that will help them to reduce this problem. This is a societal problem that is fundamental to be solved through science education, exploring it in the classroom can contribute to work on various aspects of student's scientific literacy in a Science, Technology, and Society approach. However, there are few studies focus on the ability of elementary school students to understand the impacts of the introduction of exotic species. This work evaluates the impact of a didactic sequence i) on the recognition of the danger of introducing exotic species and ii) on predicting its invasive potential. This didactic sequence was applied in two classes of the 3rd grade. Pre and post-tests were used to evaluate the results of this intervention. The results suggest that this didactic sequence contributes to the recognition of the dangers of the introduction of exotic species.

Keywords: Education for Science; Biodiversity; Exotic and Invasive Species; Didactic Activities.

Resumen La introducción de especies exóticas representa una grave amenaza para la biodiversidad, presentando las especies exóticas invasoras como las que han causado mayor impacto en los ecosistemas. Así, es necesario fomentar en los ciudadanos la comprensión de los impactos de la introducción de estas especies en la biodiversidad autóctona y en el bienestar de las personas y desarrollar conocimientos, actitudes y comportamientos que les permitan contribuir a mitigar este problema. Siendo éste un problema societal para cuya resolución la educación en ciencias es fundamental, su explotación en el aula puede contribuir a trabajar diversos aspectos de la alfabetización científica de los alumnos en un enfoque de Ciencia, Tecnología y Sociedad. Sin embargo, escasean estudios sobre la capacidad de los alumnos del primer ciclo de comprender los impactos de la introducción de especies exóticas. Este trabajo evalúa el impacto de una secuencia didáctica i) en el reconocimiento del peligro de la introducción de especies exóticas y ii) en la previsión de su potencial invasor. Esta secuencia didáctica se aplicó en 2 clases de tercer año. Los resultados fueron evaluados a través de pre y post-tests y sugieren que esta secuencia didáctica contribuye para el reconocimiento de los peligros de la introducción de especies exóticas.

Palabras clave: Educación para la Ciencia; Biodiversidad; Especies Exóticas y InvasoRAS; ActividADES DidÁcticAs.

\section{INTRODUÇÃo}

A perda acentuada da biodiversidade é um problema societal relevante, em cuja resolução a educação poderá ter um papel preponderante (HAZELKORN et al., 2015). A introdução de espécies exóticas é uma das principais ameaças à biodiversidade autóctone 
nacional (ICNF, 2017). Entre as diversas espécies exóticas introduzidas em Portugal, as que maior impacto têm causado nos ecossistemas são as espécies invasoras, pois estas têm a capacidade de se produzir e manter fora do seu ambiente autóctone, inúmeras populações separadas no espaço e no tempo (Plantas Invasoras em Portugal, 2017). As espécies exóticas invasoras têm, geralmente, crescimento rápido e/ou elevada capacidade de dispersão, maior eficiência na obtenção de recursos do que as espécies autóctones, elevada capacidade de reprodução e se beneficiam da ausência de inimigos naturais nos locais que invadem (Plantas Invasoras em Portugal, 2017). Assim, essas espécies ocupam rapidamente vastas áreas do território, das quais excluem as espécies autóctones, aumentando a probabilidade de extinção destas últimas.

Em Portugal, espera-se que à saída da escolaridade obrigatória os alunos sejam dotados de literacia científica que lhes permita analisar, questionar, avaliar e selecionar informação, formular hipóteses e tomar decisões fundamentadas (OLIVEIRA-MARTINS et al., 2017), para que possam responder aos desafios pessoais e societais que se deparam. A educação deve contribuir para a promoção do desenvolvimento sustentável, promovendo a compreensão de que os recursos são limitados e valorizando a sustentabilidade (OLIVEIRA-MARTINS et al., 2017; OCDE, 2018).

De acordo com Soga et al. (2016), espera-se que as crianças que frequentemente experimentam a natureza, por meio de contacto direto, conversas sobre meio ambiente e livros, vídeos etc., desenvolvam maior interesse, afinidade emocional e apoio à proteção da biodiversidade. Assim, urge promover essas experiências durante os primeiros anos de ensino. No entanto, escasseiam atividades educativas destinadas a crianças do $1^{\circ}$. ciclo que explorem a temática das espécies invasoras e os seus impactos na sociedade e na biodiversidade. Para além disso, não existem estudos que analisem se as crianças do $1^{\circ}$. Ciclo do Ensino Básico são capazes de compreender os impactos causados pela introdução de espécies exóticas nos ecossistemas e prever o seu potencial invasor. Com o presente trabalho, pretendemos: $i$ ) compreender o potencial de sequências didáticas que explorem a temática das espécies exóticas e invasoras para a promoção de trabalho experimental e práticas epistémicas; ii) avaliar o seu impacto nas atitudes dos alunos face à introdução de espécies exóticas, e iii) avaliar a capacidade dos alunos preverem o comportamento de uma espécie num habitat com base nas suas características biológicas.

\section{Desenvolvimento}

\section{PROBLEMA DE INVESTIGAÇÃO}

A problemática das espécies exóticas e invasoras está pouco explorada em idades precoces e existem poucas investigações que relacionem a exploração dessa temática com o desenvolvimento de outras competências e conhecimentos nos alunos. A presente investigação orientou-se pelas seguintes questões-problema:

1. De que forma a temática das espécies invasoras poderá ser explorada no âmbito dos programas e aprendizagens essenciais oficiais para o primeiro e segundo ciclo e para fomentar práticas epistêmicas? 
2. Será que essa sequência didática permite aos alunos reconhecerem os perigos associados à introdução de espécies exóticas e invasoras?

3. Será que uma abordagem educativa centrada nos perigos das espécies exóticas e invasoras permite que os alunos aprendam a prever o comportamento de espécies distintas com base nas suas características biológicas?

Para avaliar o sucesso e relevância da investigação foram definidos os seguintes objetivos de aprendizagem:

a) Reconhecer a influência no potencial invasor de uma espécie de parâmetros biológicos como a capacidade de germinação, de dispersão e de resistência a incêndios;

b) Reconhecer as consequências da introdução de espécies exóticas.

\section{Metodologia}

Para atingir os objetivos didáticos propostos desenvolveu-se uma sequência didática constituída por cinco sessões de 90 minutos. Na tabela do anexo I (também disponível em https://goo.gl/VFrdK2), podem consultar-se: a descrição de cada sessão; as atitudes e práticas epistêmicas a desenvolver (LOPES et al., 2012); os conteúdos de biologia a aprender; as competências-chave do Perfil dos alunos do século XXI (OLIVEIRA-MARTINS et al., 2017) trabalhadas em cada uma das sessões. Essas atividades foram realizadas em duas turmas do $3^{\circ}$. ano do $1^{\circ}$. Ciclo do Ensino Básico, ao ritmo de uma sessão por semana.

Na primeira sessão, para introduzir a temática, apresentamos aos alunos imagens de locais colonizados por acácias após um incêndio e pedimos que mostrassem possíveis explicações para justificar o sucesso dessa espécie naquelas condições. As hipóteses levantadas pelos alunos foram registradas no quadro. Com apoio da plataforma invasoras.pt, foram explicadas as diferenças entre espécies autóctones e exóticas e entre espécies exóticas invasoras e não invasoras. Explorou-se a galeria de imagens das espécies invasoras em Portugal, tendo-se pedido aos alunos que indicassem plantas que já tivessem visto, chamando a atenção para algumas características dessas plantas e para a sua distribuição no território português. Em seguida, foi apresentado aos alunos o jogo de tabuleiro desenvolvido (também disponível em aplicação android em https://goo.gl/9J6LFR) que simula diferentes cenários biológicos e o impacto de distintas espécies na ocupação do território, em função das suas características e dos comportamentos das pessoas face às mesmas. De acordo com Sandbrook et al. (2014), os jogos digitais criam oportunidades para a aprendizagem experiencial que é considerada mais eficaz do que a transmissão de conteúdos professor-aluno do ensino tradicional. Esse gênero de jogos pode ser usado para aumentar a consciência sobre um problema, melhorar a sua compreensão e mudar atitudes (CHIB et al., 2010).

Durante a segunda sessão, foi explorado com os alunos o impacto da capacidade de dispersão das sementes no seu sucesso ecológico. Para tal, foi pedido aos alunos que planificassem uma atividade experimental, para testar se a rápida colonização das acácias nas áreas queimadas poderia ser explicada pela maior capacidade de dispersão das suas sementes, tal como havia sido sugerido pelos alunos na primeira sessão. A atividade experimental 
foi planificada em grande grupo com recurso da ferramenta Carta de Planificação (ver anexo II, também disponível em: https://goo.gl/kxmUXu; Goldsworthy e Feasey, 1997) e realizada pelos alunos, com a orientação da docente, que os ajudou a identificarem e ultrapassarem as dificuldades no desenho e execução da experiência. Para que os alunos compreendessem o impacto da capacidade de resistência a incêndios no sucesso ecológico e no potencial invasor de uma espécie, foram ainda convidados a observar uma atividade experimental desenhada e executada pela docente (com base em Novelgro, 2014), que pretendia testar se as acácias são favorecidas por um incêndio. Foi preparada uma sementeira com sementes de acácia "não queimadas" e sementes de acácia "queimadas", a qual foi colocada nas salas de aula das duas turmas para que pudessem observar os resultados ao longo das semanas seguintes.

$\mathrm{Na}$ terceira sessão, para abordar a importância da biodiversidade e compreender os impactos das alterações de habitat na extinção de espécies, foi explorada com os alunos uma atividade de modelação dos impactos das alterações dos ecossistemas causadas pela introdução de espécies exóticas que explora ainda a importância da biodiversidade intraespecífica (a atividade da seleção natural descrita em Sá-Pinto e Campos, 2012). Ao longo dessa atividade, foram debatidos com os alunos os resultados obtidos e exploradas as suas explicações e hipóteses.

Durante a quarta sessão, para que os alunos compreendessem alguns dos impactos e consequências sociais e econômicas da introdução de espécies exóticas, lhes foram exibido vários documentos que mencionam que as plantações de eucaliptos aumentam o risco de incêndios. Foi solicitado aos alunos que apresentassem explicações para o fenômeno descrito. Nessa sessão, pediu-se aos alunos que planificassem e executassem uma atividade experimental, com recurso da carta de planificação e suporte da docente, para testar se as folhas de eucalipto voam a maiores distâncias que as das outras espécies (na experiência acácia, sobreiro e carvalho).

Na quinta sessão, os alunos foram desafiados a planificar e executar uma atividade experimental para testar se os eucaliptos têm maior facilidade de combustão. Para testar essa hipótese os alunos utilizaram as folhas de duas espécies, eucalipto e carvalho, e analisaram o tempo de combustão e a temperatura atingida. A planificação dessa atividade experimental foi realizada em grande grupo com recurso da ferramenta Carta de Planificação (ver anexo II, também disponível em: https://goo.gl/kxmUXu; Goldsworthy e Feasey, 1997) e a sua execução feita pelos alunos, com o apoio da docente que realizou as tarefas que acarretavam maior risco.

Em suma, ao longo das cinco sessões os alunos exploraram as características de espécies invasoras e as consequências da sua introdução. Foram estimulados comportamentos pró-ativos para evitar a introdução de novas espécies, fomentar a remoção de espécies invasoras e preservar a biodiversidade. Valorizou-se o conhecimento científico e a utilização de métodos científicos para responder a questões do dia a dia.

Para avaliar o potencial dessa temática para a realização de atividades experimentais em sala de aula e para o desenvolvimento de práticas epistêmicas, registraram-se todas as hipó- 
teses sugeridas pelos alunos para responder às duas questões colocadas com base nos problemas societais causados por espécies exóticas e se investigou a sua relação com as aprendizagens essenciais de Estudo do Meio (do $1^{\circ}$. ao $4^{\circ}$. ano) e Ciências Naturais ( $5^{\circ}$. e $6^{\circ}$. anos).

Desenvolveu-se um teste para avaliar os impactos da intervenção didática na capacidade dos alunos preverem o comportamento de espécies com diferentes características biológicas em diversas situações e a sua atitude face à introdução de espécies exóticas. Nesse teste, os alunos foram confrontados com a introdução de espécies exóticas, tendo-lhes sido colocadas diferentes questões que pediam que previssem cenários biológicos e dessem a sua opinião sobre o que deveria ter sido feito. O teste é introduzido por uma pequena história onde são apresentadas três plantas fictícias (Pinta, Boina e Risca) e as suas respectivas características (ver teste disponível no anexo III em: https://goo.gl/Xs4mNe). Durante o desenvolvimento do teste, e antes da sua aplicação no contexto aqui descrito, este foi sujeito a várias pilotagens, das quais resultaram algumas alterações na forma como se apresentou o problema aos alunos e na construção das diversas perguntas.

Com as quatro perguntas do teste, pretende-se avaliar, pela seguinte ordem: i) se os alunos compreendem que o sucesso ecológico de uma espécie depende do número de descendentes; ii) se reconhecem que a capacidade de dispersão de uma espécie afeta a sua distribuição espacial ao longo do tempo; iii) se compreendem que a capacidade de resistência a determinadas condições do meio (catástrofes) aumenta o seu sucesso ecológico; e $i v$ ) a atitude dos alunos face à possibilidade de introdução de espécies exóticas.

Esse teste foi aplicado aos alunos das duas turmas de terceiro ano, imediatamente antes (pré-teste) e imediatamente após (pós-teste) a realização da sequência didática já descrita. O teste foi lido para a turma e os alunos foram convidados a escrever uma previsão, justificada, em cada pergunta, podendo na terceira ilustrar as suas ideias com desenhos. A aplicação desse teste demorou entre 20 a 30 minutos.

Foi realizada uma análise de conteúdos das respostas dos alunos e para cada pergunta foram definidos critérios de análise que se encontram descritos na tabela do anexo IV (também disponível em: https://goo.gl/V5Pqmq). A avaliação dos testes foi realizada independentemente por dois investigadores - um biólogo (PC) e um docente de $1^{\circ}$. e $2^{\circ}$. Ciclo do Ensino Básico (PP). Em caso de diferenças na avaliação dos critérios, a classificação final de cada um foi obtida por consenso após análise e discussão. Para avaliar as diferenças entre os pré e os pós testes, foram feitos testes de McNemar com recurso do software SPSS v24.

Não foi recolhida qualquer informação pessoal sobre os alunos e as suas respostas foram identificadas com um código formado a partir do número e escola dos alunos. Foram solicitados consentimentos informados aos pais dos alunos e à direção das escolas, antes da implementação da atividade.

\section{Resultados}

Ao longo dessa sequência didática, os alunos avançaram 10 hipóteses explicativas para responder à questão Por que as acácias ocupam grandes áreas, após um incêndio? e oito hipóteses explicativas para a questão Por que as plantações de eucaliptos aumentam o risco de incêndio? A análise dos documentos das Aprendizagens Essenciais de Estudo 
do Meio (do $1^{\circ}$. ao $4^{\circ}$. ano) e de Ciências Naturais $\left(5^{\circ}\right.$. e $6^{\circ}$. ano) permite verificar que as hipóteses avançadas pelos alunos para explicarem os fenômenos descritos permitem trabalhar conteúdos considerados essenciais do $2^{\circ}$. ao $6^{\circ}$. ano, ver Tabela 1 .

Tabela 1 - Questões apresentadas aos alunos, respectivas hipóteses avançadas e testadas e sua inserção nas aprendizagens essenciais do $1^{\circ}$. e $2^{\circ}$. Ciclo.

\begin{tabular}{|c|c|c|c|}
\hline Questão & $\begin{array}{l}\text { Por que a } \\
\text { um incên }\end{array}$ & $\begin{array}{l}\text { acácias ocupam grandes áreas, após } \\
\text { io? }\end{array}$ & Aprendizagens essenciais em que cada hipótese poderá ser inserida \\
\hline \multirow{5}{*}{$\begin{array}{c}\text { Hipó- } \\
\text { teses } \\
\text { avança- } \\
\text { das }\end{array}$} & & Dão mais sementes; & $\begin{array}{l}3^{\mathbf{0}} \text {. ano - Reconhecer que os seres vivos se reproduzem e que os seus } \\
\text { descendentes apresentam características semelhantes aos progenito- } \\
\text { res, mas também diferem em algumas delas; } \\
\mathbf{5}^{\mathbf{0}} \text {. ano - Explicar a necessidade da intervenção de células sexuais na } \\
\text { reprodução de alguns seres vivos e a sua importância para a evolução } \\
\text { das espécies; } \\
\quad \text { - Interpretar a influência da água, da luz e da temperatura no } \\
\quad \text { desenvolvimento das plantas; } \\
6^{\mathbf{0}} \text {. ano - Reconhecer a importância dos agentes de polinização, da } \\
\text { dispersão e da germinação das sementes na manutenção das espécies } \\
\text { e equilíbrio dos ecossistemas; }\end{array}$ \\
\hline & & As sementes se espalham melhor; & $\begin{array}{l}\mathbf{6}^{\mathbf{0}} \text {. ano - Reconhecer a importância dos agentes de polinização, da } \\
\text { dispersão e da germinação das sementes na manutenção das espécies } \\
\text { e equilíbrio dos ecossistemas; }\end{array}$ \\
\hline & & A terra é melhor para ela; & $\begin{array}{l}\mathbf{3}^{\mathbf{0}} \text {. ano - Relacionar fatores do ambiente (ar, luz, temperatura, água, } \\
\text { solo) com condições indispensáveis a diferentes etapas da vida das } \\
\text { plantas e dos animais, a partir da realização de atividades experimen- } \\
\text { tais; } \\
\mathbf{5}^{\mathbf{0}} \text { ano - Interpretar a influência da água, da luz e da temperatura no } \\
\text { desenvolvimento das plantas; }\end{array}$ \\
\hline & & Dá muitas raízes; & $\begin{array}{l}2^{\mathbf{0}} \text {. ano - Categorizar os seres vivos de acordo com semelhanças e di- } \\
\text { ferenças observáveis ([...]; plantas: tipo de raiz, tipo de caule, forma } \\
\text { da folha, folha caduca/persistente, cor da flor, fruto e semente etc.); } \\
\text { Relacionar as características dos seres vivos (animais e plantas), com } \\
\text { o seu habitat. } \\
\mathbf{3}^{\mathbf{0}} \text { ano - Realizar experiências e observar formas de reprodução das } \\
\text { plantas (germinação das sementes, reprodução por estaca...); } \\
6^{\mathbf{0}} \text {. ano - Reconhecer a importância dos agentes de polinização, da } \\
\text { dispersão e da germinação das sementes na manutenção das espécies } \\
\text { e equilíbrio dos ecossistemas; }\end{array}$ \\
\hline & & Dá-se bem durante o ano todo; & $\begin{array}{l}\mathbf{3}^{\mathbf{0}} \text {. ano - Relacionar fatores do ambiente (ar, luz, temperatura, água, solo) } \\
\text { com condições indispensáveis a diferentes etapas da vida das plantas e } \\
\text { dos animais, a partir da realização de atividades experimentais; } \\
\\
\mathbf{5}^{\mathbf{0}} \text {. ano - Interpretar a influência da água, da luz e da temperatura no } \\
\text { desenvolvimento das plantas; }\end{array}$ \\
\hline
\end{tabular}




\begin{tabular}{|c|c|c|}
\hline $\begin{array}{l}\text { Ques- } \\
\text { tão }\end{array}$ & $\begin{array}{l}\text { Por que as acácias ocupam grandes áreas, após } \\
\text { um incêndio? }\end{array}$ & Aprendizagens essenciais em que cada hipótese poderá ser inserida \\
\hline & 6. Dá novas plantas; & $\begin{array}{l}\mathbf{3}^{\circ} \text {. ano - Reconhecer que os seres vivos se reproduzem e que os } \\
\text { seus descendentes apresentam características semelhantes aos proge- } \\
\text { nitores, mas também diferem em algumas delas; } \\
\text { - Relacionar fatores do ambiente (ar, luz, temperatura, água, } \\
\text { solo) com condições indispensáveis a diferentes etapas da vida } \\
\text { das plantas e dos animais, a partir da realização de atividades } \\
\text { experimentais; } \\
\mathbf{5}^{\circ} \text {. ano - Explicar a necessidade da intervenção de células sexuais } \\
\text { na reprodução de alguns seres vivos e a sua importância para a } \\
\text { evolução das espécies; } \\
\quad \text { - Interpretar a influência da água, da luz e da temperatura no } \\
\text { desenvolvimento das plantas; } \\
\mathbf{6}^{\mathbf{0}} \text {. ano - Reconhecer a importância dos agentes de polinização, da } \\
\text { dispersão e da germinação das sementes na manutenção das espécies } \\
\text { e equilíbrio dos ecossistemas; }\end{array}$ \\
\hline & 7. Aproveita melhor o alimento; & $\begin{array}{l}\mathbf{3}^{\circ} \text {. ano - Relacionar fatores do ambiente (ar, luz, temperatura, água, } \\
\text { solo) com condições indispensáveis a diferentes etapas da vida das } \\
\text { plantas e dos animais, a partir da realização de atividades experi- } \\
\text { mentais; } \\
\mathbf{5}^{\circ} \text {. ano - Interpretar a influência da água, da luz e da temperatura no } \\
\text { desenvolvimento das plantas; } \\
6^{\text {. }} \text { ano - Explicar a importância da fotossíntese para a obtenção de } \\
\text { alimento nas plantas relacionando os produtos da fotossíntese com a } \\
\text { respiração celular; }\end{array}$ \\
\hline & 8. Tem mais espaço disponível; & $\begin{array}{l}\mathbf{3}^{\mathbf{0}} \text {. ano - Relacionar fatores do ambiente (ar, luz, temperatura, água, } \\
\text { solo) com condições indispensáveis a diferentes etapas da vida das } \\
\text { plantas e dos animais, a partir da realização de atividades experi- } \\
\text { mentais; } \\
\text { 6. }^{\mathbf{0}} \text { ano - Reconhecer a importância dos agentes de polinização, da } \\
\text { dispersão e da germinação das sementes na manutenção das espécies } \\
\text { e equilíbrio dos ecossistemas; }\end{array}$ \\
\hline & 9. Crescem mais rápido; & $\begin{array}{l}\mathbf{3}^{\circ} \text {. ano - Relacionar fatores do ambiente (ar, luz, temperatura, água, } \\
\text { solo) com condições indispensáveis a diferentes etapas da vida das } \\
\text { plantas e dos animais, a partir da realização de atividades experi- } \\
\text { mentais; } \\
5^{\circ} \text {. ano - Interpretar a influência da água, da luz e da temperatura no } \\
\text { desenvolvimento das plantas; } \\
\mathbf{6}^{\circ} \text {. ano - Explicar a importância da fotossíntese para a obtenção de } \\
\text { alimento nas plantas relacionando os produtos da fotossíntese com a } \\
\text { respiração celular; } \\
\text { - Reconhecer a importância dos agentes de polinização, da dispersão } \\
\text { e da germinação das sementes na manutenção das espécies e equilí- } \\
\text { brio dos ecossistemas; }\end{array}$ \\
\hline & $\begin{array}{l}\text { 10. Raízes com veneno para atacar as ou- } \\
\text { tras; }\end{array}$ & $\begin{array}{l}\mathbf{5}^{\circ} \text {. ano-Caracterizar alguma biodiversidade existente a nível local, } \\
\text { regional e nacional, apresentando exemplos de relações entre a flora } \\
\text { e a fauna nos diferentes habitats; }\end{array}$ \\
\hline
\end{tabular}




\begin{tabular}{|c|c|c|}
\hline Questão & $\begin{array}{l}\text { Por que as acácias ocupam grandes áreas, após } \\
\text { um incêndio? }\end{array}$ & Aprendizagens essenciais em que cada hipótese poderá ser inserida \\
\hline & $\begin{array}{l}\text { Capacidade de dispersão das sementes causada } \\
\text { pelo vento }\end{array}$ & $\begin{array}{l}6^{0} \text {. ano - Reconhecer a importância dos agentes de polinização, da } \\
\text { dispersão e da germinação das sementes na manutenção das espécies } \\
\text { e equilíbrio dos ecossistemas; }\end{array}$ \\
\hline $\begin{array}{l}\text { Hipó- } \\
\text { teses } \\
\text { testadas }\end{array}$ & $\begin{array}{l}\text { Capacidade de resistência a incêndios através das } \\
\text { sementes }\end{array}$ & $\begin{array}{l}\mathbf{3}^{\circ} \text {. ano - Relacionar fatores do ambiente (ar, luz, temperatura, água, } \\
\text { solo) com condições indispensáveis a diferentes etapas da vida das } \\
\text { plantas e dos animais, a partir da realização de atividades experi- } \\
\text { mentais; } \\
6^{\text {o. }} \text { ano - Reconhecer a importância dos agentes de polinização, da } \\
\text { dispersão e da germinação das sementes na manutenção das espécies } \\
\text { e equilíbrio dos ecossistemas; }\end{array}$ \\
\hline Questão & $\begin{array}{l}\text { Por que as plantações de eucaliptos aumentam o } \\
\text { risco de incêndio? }\end{array}$ & Aprendizagens essenciais em que cada hipótese poderá ser inserida \\
\hline \multirow{8}{*}{$\begin{array}{l}\text { Hipó- } \\
\text { teses } \\
\text { avança- } \\
\text { das }\end{array}$} & 1) Queimam mais rápido; & $\begin{array}{l}6^{0} . \text { ano - Discutir a importância das plantas para a vida na Terra e } \\
\text { medidas de conservação da floresta autóctone; }\end{array}$ \\
\hline & Estão plantadas todas juntas; & $\begin{array}{l}6^{0} . \text { ano - Discutir a importância das plantas para a vida na Terra e } \\
\text { medidas de conservação da floresta autóctone; }\end{array}$ \\
\hline & Têm mais resina; & $\begin{array}{l}\mathbf{2}^{\circ} \text {. ano - Categorizar os seres vivos de acordo com semelhanças } \\
\text { e diferenças observáveis ([[..]; plantas: tipo de raiz, tipo de caule, } \\
\text { forma da folha, folha caduca/persistente, cor da flor, fruto e semente } \\
\text { etc.). } \\
\mathbf{2}^{\mathbf{o}} \text {. ano - Relacionar as características dos seres vivos (animais e } \\
\text { plantas), com o seu habitat. }\end{array}$ \\
\hline & São mais secas, têm menos água; & 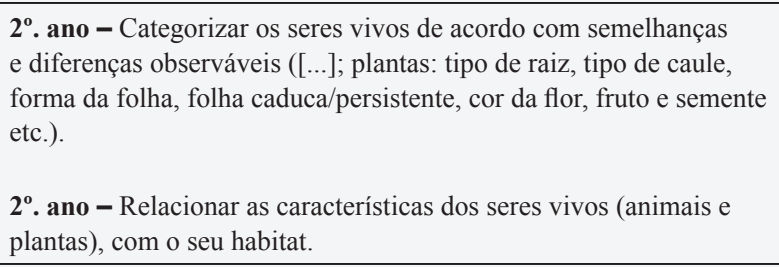 \\
\hline & $\begin{array}{l}\text { 5) Espalham mais rápido o incêndio por } \\
\text { ter muitas folhas; }\end{array}$ & $\begin{array}{l}\mathbf{2}^{\mathbf{o}} \text {. ano - Categorizar os seres vivos de acordo com semelhanças } \\
\text { e diferenças observáveis ([...]; plantas: tipo de raiz, tipo de caule, } \\
\text { forma da folha, folha caduca/persistente, cor da flor, fruto e semente } \\
\text { etc.). } \\
\mathbf{2}^{\mathbf{o}} \text {. ano - Relacionar as características dos seres vivos (animais e } \\
\text { plantas), com o seu habitat. }\end{array}$ \\
\hline & São mais inflamáveis no tronco; & $\begin{array}{l}6^{\circ} \text {. ano - Discutir a importância das plantas para a vida na Terra e } \\
\text { medidas de conservação da floresta autóctone; }\end{array}$ \\
\hline & São mais inflamáveis nas folhas; & $\begin{array}{l}\mathbf{6}^{0} . \text { ano - Discutir a importância das plantas para a vida na Terra e } \\
\text { medidas de conservação da floresta autóctone; }\end{array}$ \\
\hline & $\begin{array}{l}\text { São mais inflamáveis por causa da } \\
\text { casca que o tronco larga; }\end{array}$ & $\begin{array}{l}6^{\circ} . \text { ano - Discutir a importância das plantas para a vida na Terra e } \\
\text { medidas de conservação da floresta autóctone; }\end{array}$ \\
\hline
\end{tabular}




\begin{tabular}{|c|c|c|}
\hline $\begin{array}{l}\text { Ques- } \\
\text { tão }\end{array}$ & $\begin{array}{l}\text { Por que as acácias ocupam grandes áreas, após } \\
\text { um incêndio? }\end{array}$ & Aprendizagens essenciais em que cada hipótese poderá ser inserida \\
\hline \multirow[t]{2}{*}{$\begin{array}{l}\text { Hipó- } \\
\text { teses } \\
\text { testadas }\end{array}$} & Folhas de eucalipto voam maiores distâncias & $\begin{array}{l}\mathbf{2}^{\circ} . \text { ano - Categorizar os seres vivos de acordo com semelhanças } \\
\text { e diferenças observáveis ([...]; plantas: tipo de raiz, tipo de caule, } \\
\text { forma da folha, folha caduca/persistente, cor da flor, fruto e semen- } \\
\text { te etc.). } \\
\mathbf{2}^{\mathbf{0}} \text {. ano - Relacionar as características dos seres vivos (animais e } \\
\text { plantas), com o seu habitat. }\end{array}$ \\
\hline & Capacidade de combustão das folhas & $\begin{array}{l}6^{0} . \text { ano - Discutir a importância das plantas para a vida na Terra e } \\
\text { medidas de conservação da floresta autóctone; }\end{array}$ \\
\hline \multicolumn{2}{|c|}{ Aprendizagens essenciais transversais a todas as hipóteses } & 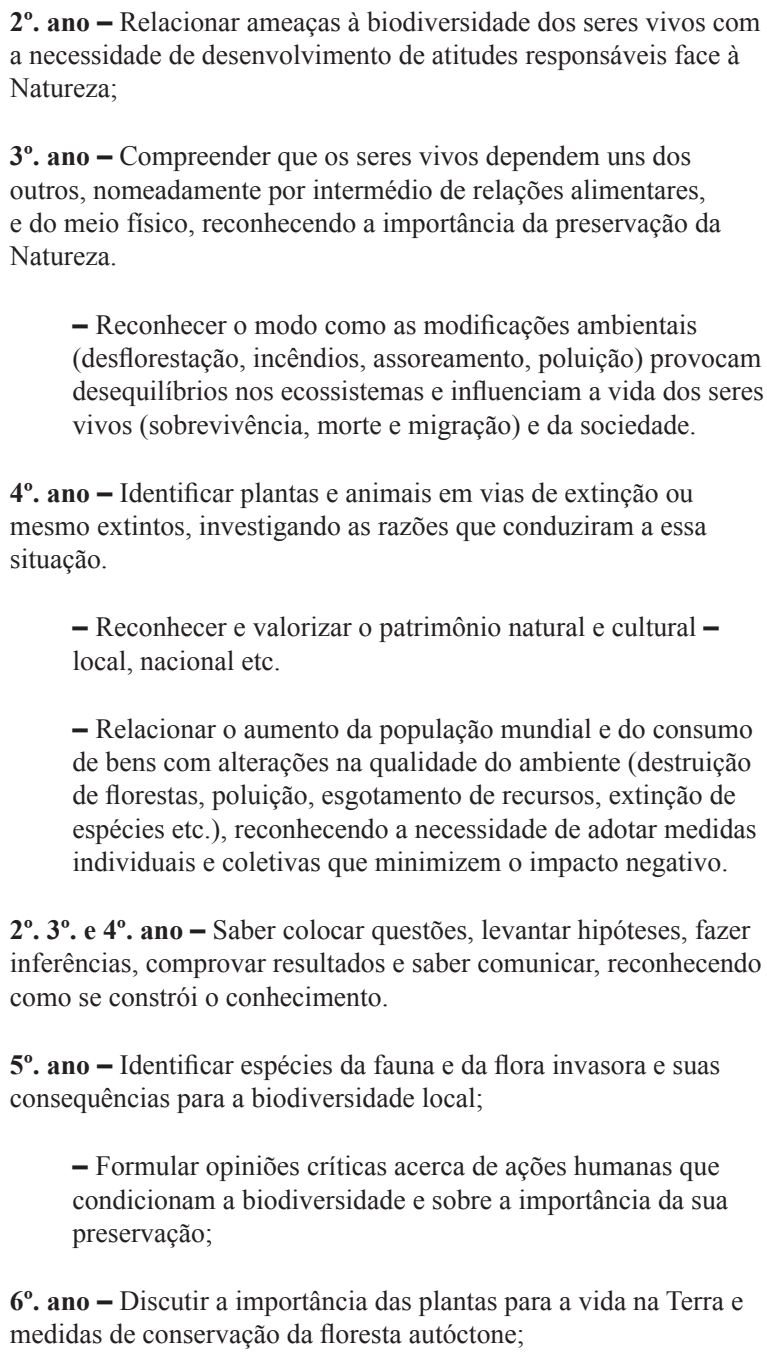 \\
\hline
\end{tabular}


Os resultados relativos às respostas dos alunos ao teste antes e depois da intervenção educativa se encontram descritos na Tabela 2 (ver os gráficos correspondentes aos mesmos resultados no anexo $\mathrm{V}$, também disponível em: https://goo.gl/UBemxh). A definição e exemplos de respostas classificadas como pertencentes a cada um dos critérios podem ser consultados no anexo IV (também disponível em: https://goo.gl/V5Pqmq).

Tabela 2 - Resultados obtidos em cada questão no pré e pós-teste nos vários critérios definidos

\begin{tabular}{|c|c|c|c|c|c|c|c|c|c|c|}
\hline & 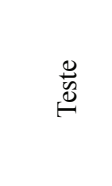 & & $\stackrel{\text { 䒿 }}{\Xi}$ & : & 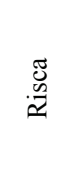 & $\begin{array}{l}\text { 节 } \\
\text { 节 } \\
\text { Z }\end{array}$ & 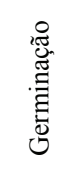 & 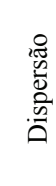 & 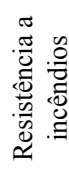 & 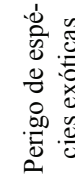 \\
\hline \multirow{2}{*}{ Questão 1} & Pré-teste & $\frac{\pi}{0}$ & $\frac{45}{0.40}$ & $\begin{array}{l}\frac{45}{0.60} \\
0.60\end{array}$ & $\frac{1}{1}$ & & $\frac{45}{0.4}$ & $\frac{44}{0.11}$ & $\frac{45}{0,22}$ & $\frac{1}{1}$ \\
\hline & Pós-teste & $\frac{\pi}{0}$ & $\frac{45}{0.40}$ & $\frac{45}{0.58}$ & 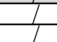 & & $\frac{45}{0.62}$ & 44 & $\frac{45}{022}$ & \\
\hline \multirow{2}{*}{ Questão 2} & Pré-teste & $\frac{\pi}{0}$ & $\frac{44}{0.43}$ & $\frac{44}{0.57}$ & $\frac{44}{0}$ & & $\frac{44}{0.12}$ & $\frac{44}{0.6}$ & $\frac{44}{0.07}$ & \\
\hline & Pós-teste & $\frac{N}{0}$ & $\frac{44}{0.30}$ & 0.68 & $\frac{44}{0.02}$ & & $\frac{44}{0.11}$ & $\frac{44}{0.75}$ & $\frac{44}{0.02}$ & \\
\hline \multirow{2}{*}{ Questão 3} & Pré-teste & $\frac{1}{0}$ & $\frac{45}{067}$ & $\frac{45}{0.02}$ & $\frac{45}{0}$ & & 45 & $\frac{15}{45}$ & $\frac{0,5}{45}$ & 7 \\
\hline & Pós-teste & $\frac{0}{0}$ & $\frac{01}{45}$ & $\frac{0}{45}$ & $\frac{45}{45}$ & $\frac{1}{1}$ & $\frac{45}{40}$ & 44 & 45 & $\frac{1}{1}$ \\
\hline \multirow{3}{*}{ Questão 4} & Pré-teste & $\frac{70}{N}$ & $\frac{104}{43}$ & 43 & $\frac{13}{43}$ & 43 & 43 & 43 & 43 & 43 \\
\hline & 110-соле & $\frac{0}{N}$ & $\frac{0.60}{43}$ & $\frac{0,16}{43}$ & $\frac{0.06}{43}$ & $\frac{0.14}{43}$ & $\frac{0}{43}$ & $\frac{0}{43}$ & $\frac{0}{43}$ & $\frac{0}{42}$ \\
\hline & Pós-teste & $\%$ & 0,30 ** & 0,07 & 0,0 & $0,51 *$ & 0,0 & 0,02 & 0 & $0,40^{*}$ \\
\hline
\end{tabular}

Legenda: $\mathrm{N}$ - número de respostas que puderam ser claramente classificadas para cada critério; \% - percentagem de respostas atribuídas a cada critério; ** - valor significativamente diferente do resultado no pré-teste com testes McNemar, p-valor inferior a $0.01 ; /$ - critério não aplicado.

Relativamente à questão Ao fim de 5 anos qual dos quintais terá mais plantas? O do Antônio (pinta) ou o do Tomás (boina)? Por quê? (questão 1), no pré-teste, a maioria dos alunos escolhe a planta com maior capacidade de reprodução, justificando com o maior número de descendentes que germinam. No pós-teste não se verificam diferenças significativas relativamente ao pré-teste ( $\mathrm{p}>0.05$ nos testes de McNemar relativos a todos os critérios analisados).

Relativamente à questão 2: Ao fim de 6 anos uma das plantas apareceu no quintal do Luís, que ficou chateado por ter no seu quintal uma planta que não tinha plantado. Qual você acha que foi? Por quê?", no pré-teste, a maioria dos alunos acredita ter sido a boina, justificando a sua resposta com a maior capacidade de dispersão dessa planta. Embora o número de alunos que escolheram essa espécie e justificaram a sua previsão com base na capacidade de dispersão aumente no pós-teste, essas diferenças não são estatisticamente significativas ( $\mathrm{p}>0.05$ nos testes de McNemar relativos a todos os critérios analisados).

Relativamente à questão 3: Passado 10 anos os quintais foram atingidos por um incêndio que queimou todas as plantas. Durante esse ano nenhum dos vizinhos plantou nada nos seus quintais. Como você pensa que estarão os quintais passado um ano? Justifique a sua resposta e faça a sua ilustração na Figura 2. Quer no pré-teste, quer no pós-teste, a maioria dos alunos respondeu que nos quintais existiria a Pinta, justificando com o fato 
de essa planta ser resistente a incêndios. Não se verificaram diferenças estatisticamente significativas entre o pré e o pós-teste ( $\mathrm{p}>0.05$ no teste de McNemar relativos a todos os critérios analisados).

Na Figura 1 é apresentado o gráfico correspondente aos resultados obtidos nos pré e pós-teste para a questão 4: Se você tivesse estado no viveiro com os dois amigos, que conselho daria sobre a recordação que deveriam trazer?

Figura 1 - Gráfico dos resultados obtidos em cada critério nos pré e pós-teste na questão 4

\section{Questão 4}

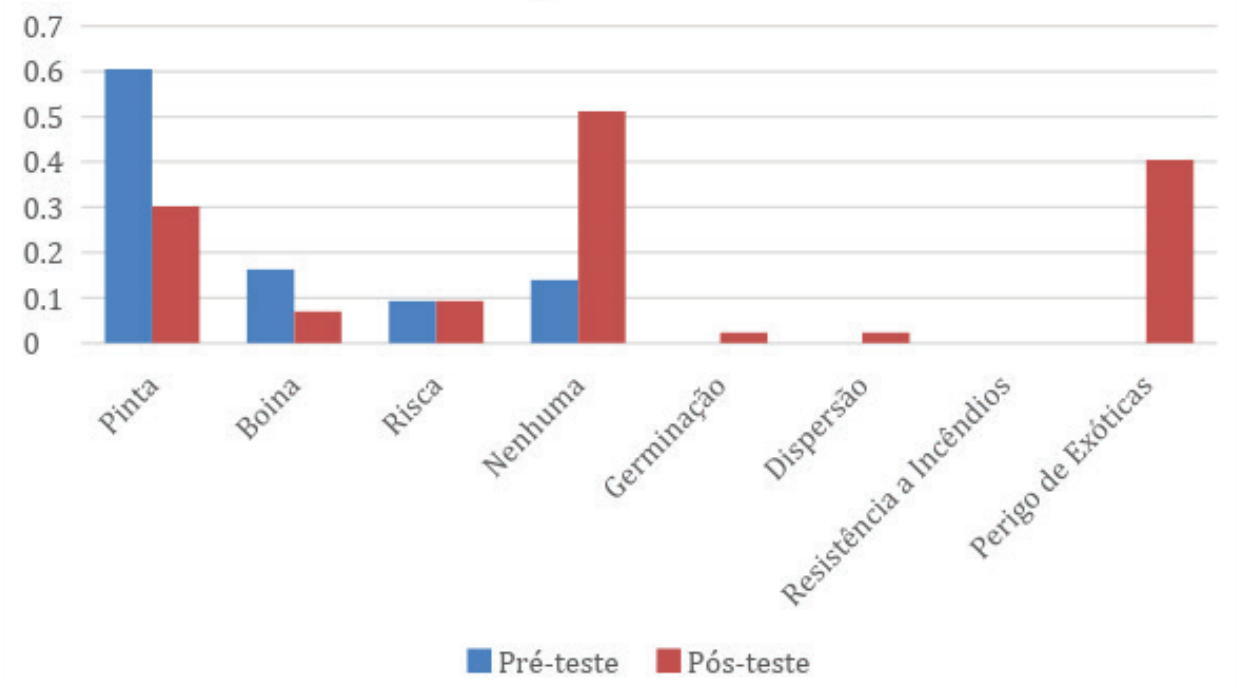

Na questão 4, no pré-teste, a maioria dos alunos escolheria trazer a Pinta, justificando essa escolha com as características da planta e gosto pessoal. No pós-teste, verifica-se uma diminuição significativa do número de alunos que escolhem trazer plantas exóticas, nomeadamente da planta Pinta $(\mathrm{p}=0.002)$ e um aumento significativo do número de alunos que referem não trazer Nenhuma planta $(\mathrm{p}=0.000)$. No pós-teste, verifica-se também um aumento significativo dos alunos que justificam a sua escolha com o perigo de introdução de espécies exóticas (Perigo de Exóticas) $(\mathrm{p}=0.000)$, justificação inexistente no pré-teste.

\section{Discussão}

Os nossos resultados mostram que a apresentação de fenômenos e impactos causados por espécies exóticas fomenta a colocação de diversas hipóteses por parte dos alunos, como é possível verificar na Tabela 1. Na presente atividade, apenas foi possível testar quatro das 18 hipóteses levantadas pelos alunos, mas todas as hipóteses podem ser exploradas no âmbito de aprendizagens consideradas essenciais do $2^{\circ}$. ao $6^{\circ}$. ano de escolaridade. Estas 
permitem ainda aos alunos realizar diversas práticas epistêmicas, fundamentais para desenvolver aprendizagens essenciais no $2^{\circ}$. $3^{\circ}$. e $4^{\circ}$. anos.

Relativamente aos conhecimentos relativos aos impactos das espécies invasoras e sua relação com as suas características biológicas, os resultados obtidos, nas questões 1, 2 e 3 (Germinação, Dispersão e Resistência a Incêndios respectivamente), mostram que a exposição à sequência didática não resultou em diferenças significativas nas respostas. No entanto, é de salientar que já no pré-teste a maioria dos alunos foi capaz de fazer previsões corretas e justificá-las usando corretamente as características biológicas das espécies. Isso sugere que, nessa idade, os alunos são capazes de identificar parâmetros biológicos de interesse, sugerindo a existência de potencial para a utilização de atividades educacionais que usam a modelação matemática para potenciar a aprendizagem da biologia (NATIONAL RESEARCH COUNCIL, 2007), possibilitando a mudança do ensino da biologia de aquisição de saberes factuais para a aquisição dos processos.

Após a análise dos testes, foram identificados alguns reajustes que achamos necessário fazer para uma melhor recolha de dados numa futura aplicação. Na questão 1, observou-se que uma grande quantidade de alunos confundiu a informação fornecida acerca da germinação das plantas, que poderá ter contribuído para a não alteração da previsão da planta com maior sucesso ecológico. Embora se tenha contornado esse problema por meio da redefinição dos critérios e a maioria dos alunos tenha indicado a justificação mais adequada, consideramos importante tornar mais clara a apresentação dessa informação no texto. Na questão 2, a forma como apresentamos a capacidade de dispersão deu origem a dois tipos de previsões válidas. Ao indicar que as sementes de uma planta são levadas pelo vento para longe e as sementes de outra planta são levadas pelo vento para muito longe, questionando os alunos sobre qual terá aparecido no quintal do vizinho, nem todos indicam a planta com maior capacidade de dispersão, considerando que "muito longe" seria uma distância maior que a distância que separa os quintais dos vizinhos. Numa aplicação futura, essa dualidade de respostas poderá ser resolvida utilizando medidas da dispersão em metros, para tornar a análise dos resultados mais simples e objetiva. Na questão 3, surgiram algumas dificuldades em avaliar as respostas devido à interpretação do desenho e achamos que poderão ser resolvidas com a realização de entrevistas posteriores.

Relativamente à questão 4 , foi possível verificar diferenças significativas e, embora se tenham criado vários critérios para as justificações dos alunos, a grande maioria apresentou a justificação mais abrangente (Perigo de Espécies Exóticas). Esses resultados sugerem que a exposição à sequência didática induz mudanças de atitude nos alunos face à introdução de espécies exóticas. Realmente, no momento do pré-teste nenhum aluno apresentou qualquer preocupação sobre o fato de transportar plantas para diferentes habitats. Após a exposição à sequência didática descrita, a maioria dos alunos apresenta essa preocupação e escolhe não trazer planta alguma. Esses resultados suportam a importância da educação ambiental, revelando que esta poderá constituir uma ferramenta valiosa na promoção de ações pró-ambientais, aquisição de conhecimento, mudanças de atitude e comportamentos (KRASNY e DILLON, 2013; STEVENSON et al., 2013). Segundo Rakotomamonjy et 
al. (2015), proporcionar atividades de educação ambiental demonstra ter efeitos positivos mensuráveis e duradouros. Mesmo que o conhecimento por si só não leve automaticamente a atitudes positivas em relação à conservação da natureza, é visto como um pré-requisito necessário para o desenvolvimento de atitudes positivas (HEBERLEIN, 2012). Assim, os resultados aqui obtidos são encorajadores, uma vez que os alunos parecem ter compreendido os perigos associados à introdução de espécies exóticas, permitindo ainda aos alunos explorarem conteúdos e realizar práticas epistêmicas fundamentais para o desenvolvimento de Aprendizagens Essenciais do $2^{\circ}$. ao $6^{\circ}$. ano de escolaridade.

\section{CONSIDERAÇões FINAIS}

A abordagem aqui apresentada reúne atividades projetadas para desenvolver atitudes, competências, conhecimentos na área da biologia e promover práticas epistêmicas. Para que os alunos compreendessem as características de espécies exóticas invasoras e as consequências da introdução de espécies exóticas, recorremos a jogos, à utilização de atividades de modelação e à planificação e execução de atividades experimentais para testar hipóteses explicativas de fenômenos causados pela introdução de espécies invasoras. Embora sejam necessários mais estudos, os resultados aqui obtidos suportam o potencial da exploração de temáticas societais para a promoção de aprendizagens essenciais no primeiro e segundo ciclos do Ensino Básico.

\section{REFERÊNCIAS}

CHIB, A. I., LWIN, M. O., LEE, Z., NG, V. W., \& WONG, P. H. Learning AIDS in Singapore: Examining the effectiveness of HIV/AIDS efficacy messages for adolescents using ICTs. Knowledge Management \& E-Learning: An International Journal (KM\&EL), 2(2), 169-187, 2010. Download from site: http://kmel-journal.org/ojs/index. php/online-publication/article/view/61/46

GOLDSWORTHY, A., FEASEY, R. Making Sense of Primary Science Investigations. Hatfield: ASE, 1997.

HAZELKORN, E., RYAN, C., BEERNAERT, Y., CONSTANTINOU, C. P., DECA, L., GRANGEAT, M., KARIKORPI, M., LAZOUDIS, A., CASULLERAS, R. P., WELZEL-BREUER, M. Science Education for responsible Citizenship. Luxemburg: European Union, 2015.

HEBERLEIN, T.A. Navigating Environmental Attitudes; Oxford, UK: Oxford University Press, 2012.

ICNF - http://www.icnf.pt/portal/pn/biodiversidade/patrinatur/especies/n-indig/n-ind. Consultado em 2017.

226 Comunicações | Piracicaba | v. 26 | n. 2 | p. 213-242 | maio-ago. 2019 
KRASNY, M. E.; DILlON, J. (Orgs.). Trading Zones in Environmental Education; New York, NY, USA: Peter Lang, 2013.

LOPES, J. B., SILVA, A. A., CRAVINO, J. P., VIEGAS, C., CUNHA, A. E., SARAIVA, E., . . . SANTOS, C. A. Apresentação de ferramentas de ajuda a mediação dos professores de ciências físicas. Revista do Centro de Investigação e Inovação em Educação. SENSOS, 2012.

NATIONAL RESEARCH COUNCIL. Taking science to school. Learning and teaching science in grades K-8. Washington, DC: The National Academies Press, 2007.

NOVELGRO. How to germinate Acacia Crassicarpa seed - Novelgro Method (vídeo). Disponível em: https://www.youtube.com/watch? $\mathrm{v}=\mathrm{wN} 5 \mathrm{rPHekVSY \& t=136s,} 2014$.

OECD. The future of education and skills Education 2030, 2018. Disponível em: http://www.oecd.org/education/2030/OECD\%20Education\%202030\%20Position\%20Paper.pdf, 2018.

OLIVEIRA-MARTINS, G., et al. Perfil dos Alunos à Saída da Escolaridade Obrigatória. Lisboa: Ministério da Educação, 2017.

PLANTAS INVASORAS EM PORTUGAL. Disponível em: http://invasoras.pt/. Consultado em: 27/10/2017.

RAKOTOMAMONJY, S. N.; JONES, J. P. G.; RAZAFIMANAHAKA, J. H.; RAMAMONJISOA, B.; WILLIAMS, S. J. The effects of environmental education on children's and parents' knowledge and attitudes towards lemurs in rural Madagascar. Anim. Conserv. 18, 157-166, 2015.

SANDBROOK, C., W. ADAMS, AND B. MONTEFERRI. Digital games and biodiversity conservation. Conservation Letters, 2014. doi: 10.1111/conl.12113.

SÁ-PINTO, X., CAMPOS, R. As borboletas da Floresta Amarela. Vairão: Cibio - Centro de Investigação em Biodiversidade e Recursos Genéticos, 2012. Disponível em: https:// goo.gl/65Z8cq

SOGA, M.; GASTON, K. J.; YAMAURA, Y.; KURISU, K.; HANAKI, K. Both direct and vicarious experiences of nature affect children's willingness to conserve biodiversity. Int. J. Environ. Res. Public Health, 13, 529, 2016.

STEVENSON, R. B.; BRODY, M.; DILLON, J.; WALS, A. E. J. (Orgs.). International Handbook of Research on Environmental Education; Routledge: New York, NY, USA; London, UK, 2013. 


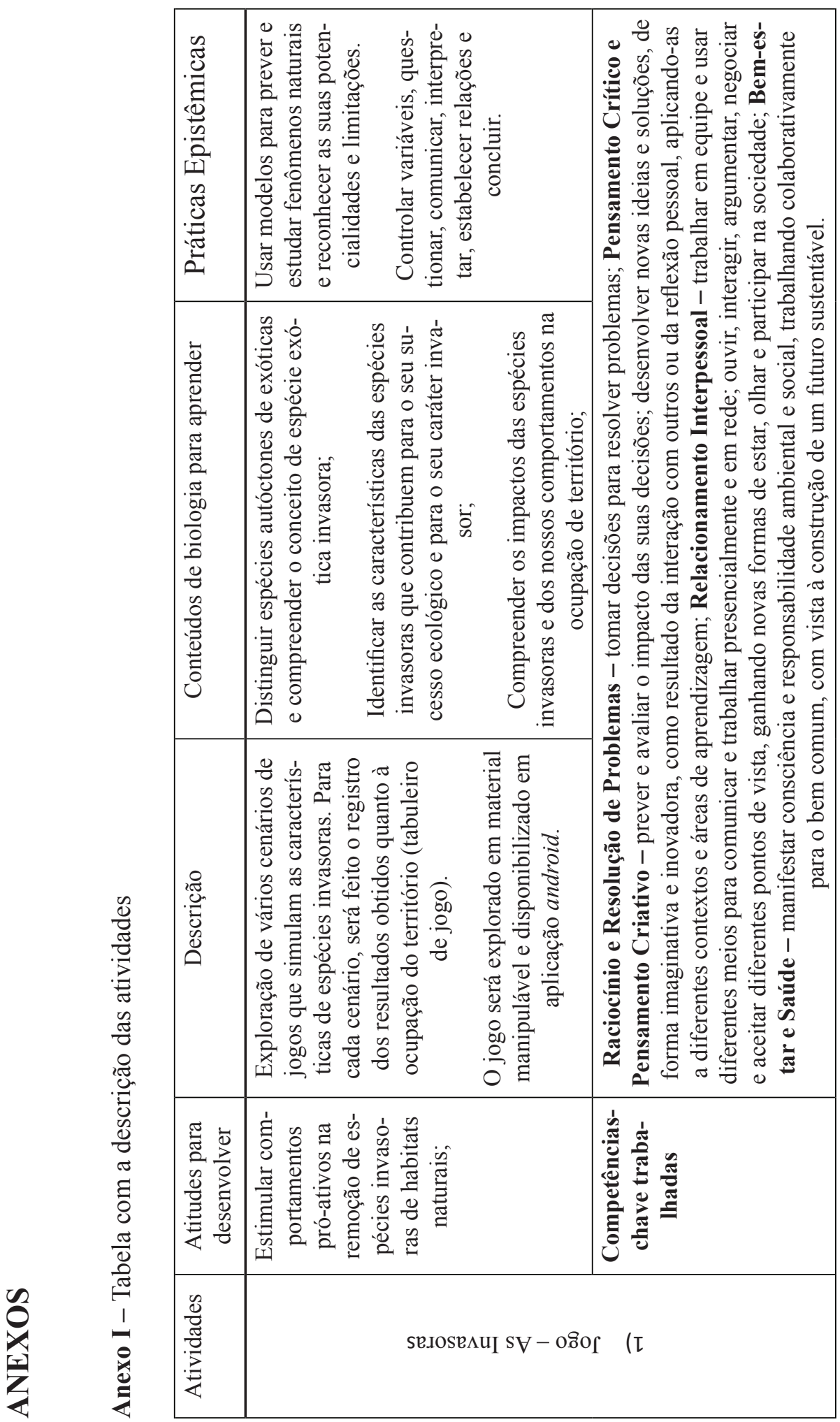

228 Comunicações | Piracicaba | v. 26 | n. 2 | p. 213-242 | maio-ago. 2019 


\begin{tabular}{|c|c|c|c|}
\hline .0 & 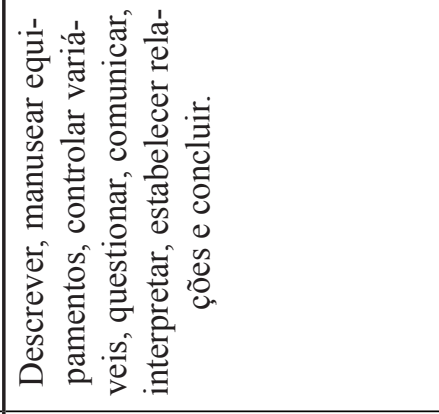 & & 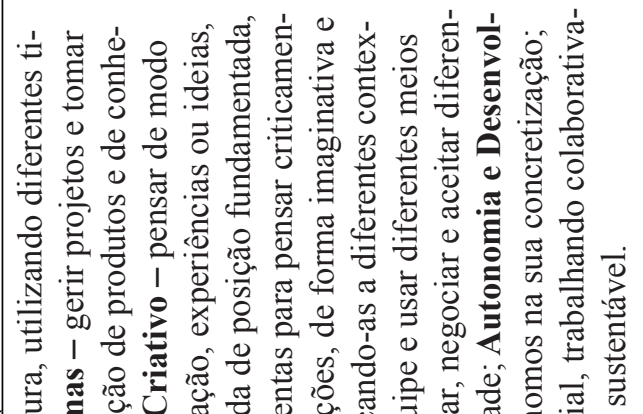 \\
\hline 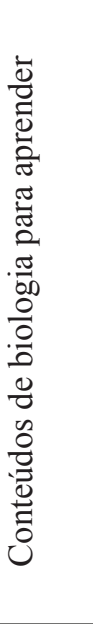 & 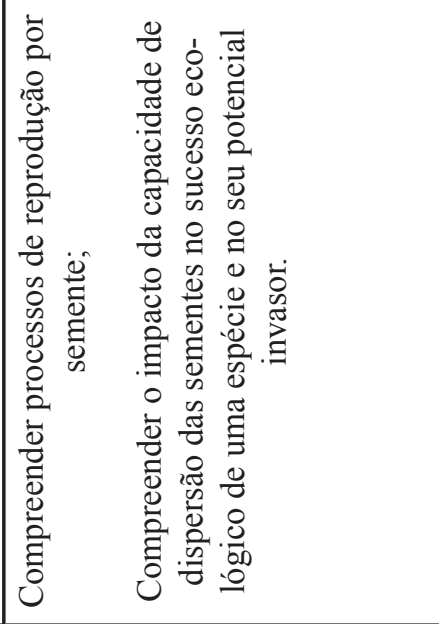 & & 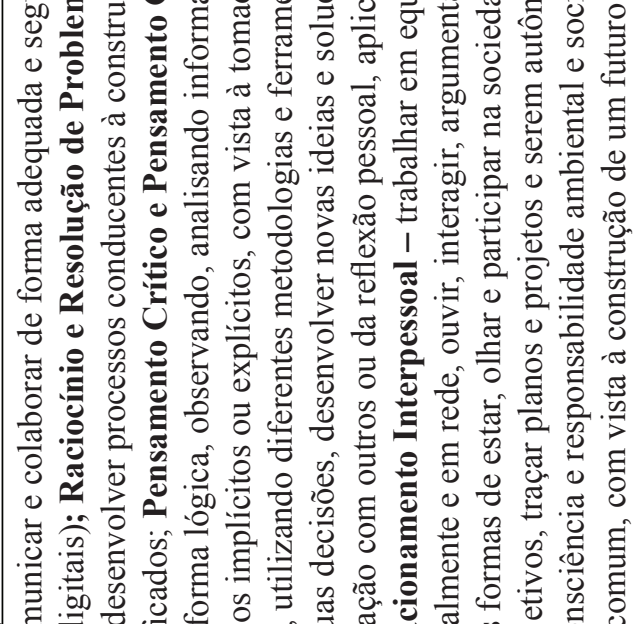 \\
\hline & 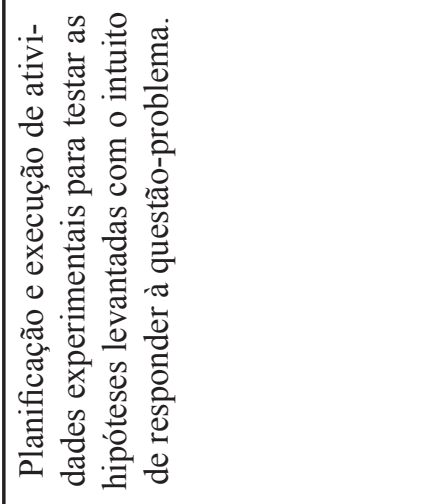 & & 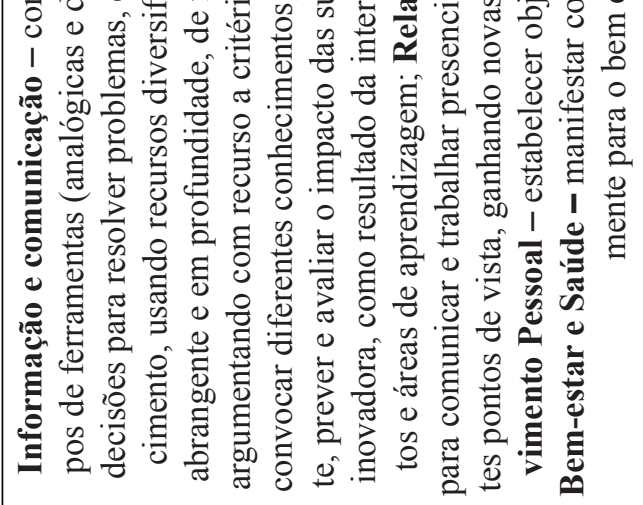 \\
\hline 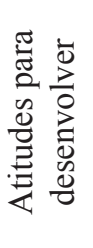 & 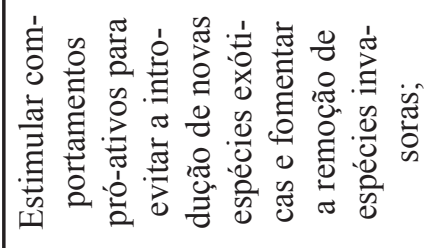 & 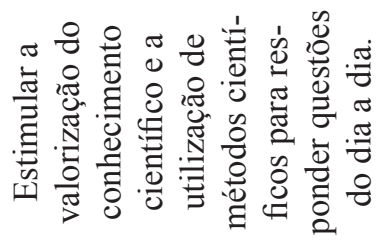 & 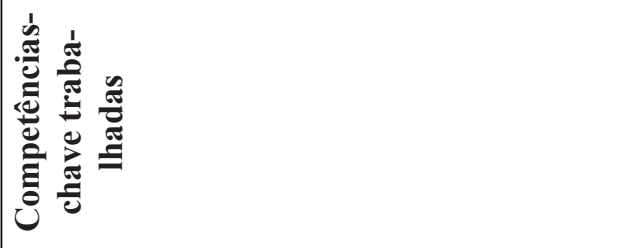 \\
\hline 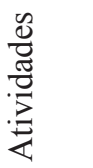 & & \multicolumn{2}{|c|}{ 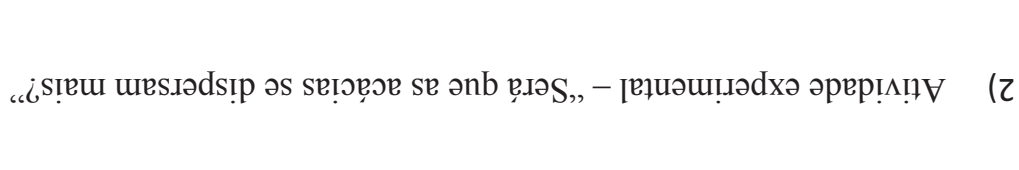 } \\
\hline
\end{tabular}




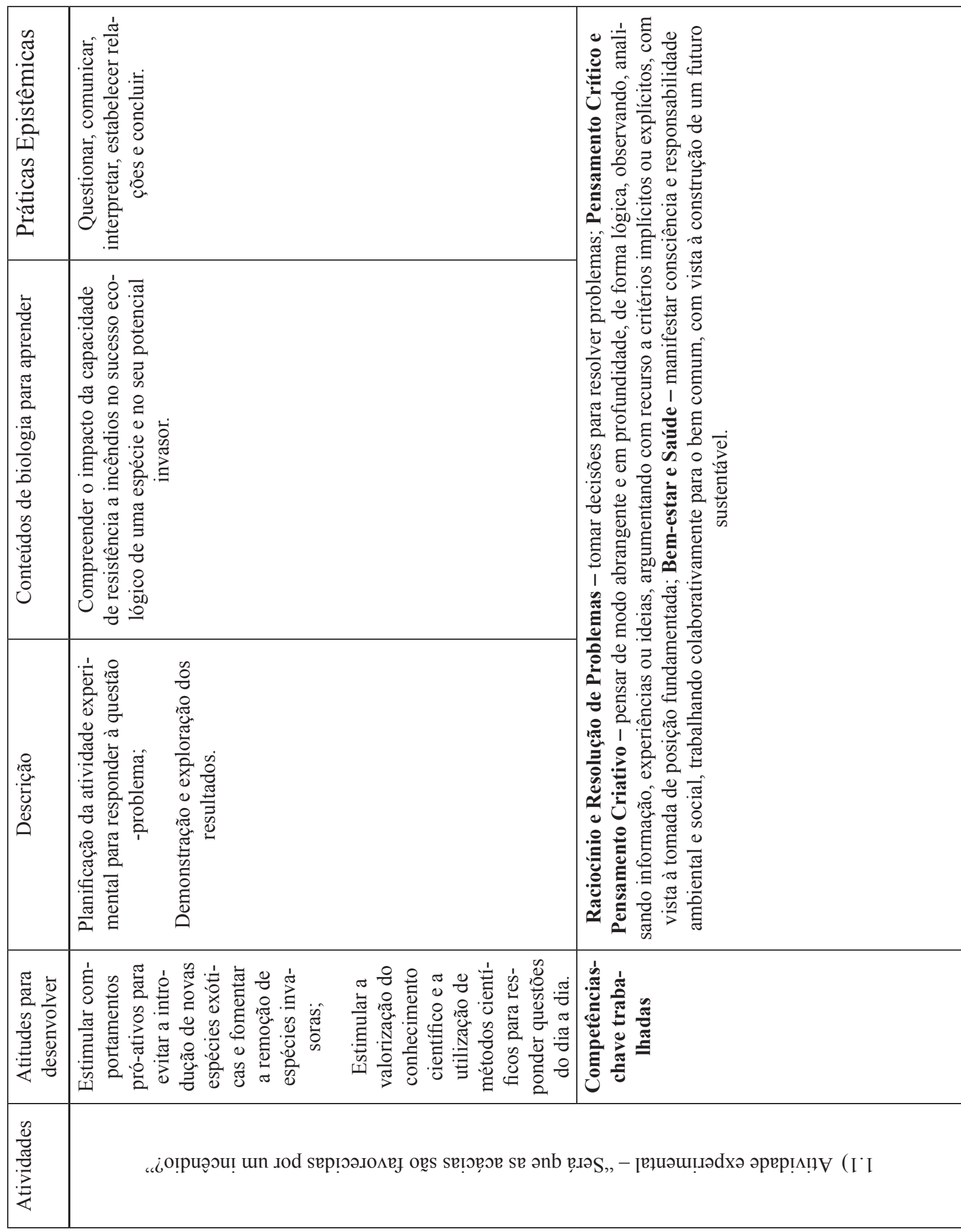

230 Comunicações | Piracicaba | v. 26 | n. 2 | p. 213-242 | maio-ago. 2019 


\begin{tabular}{|c|c|c|}
\hline 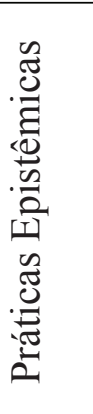 & 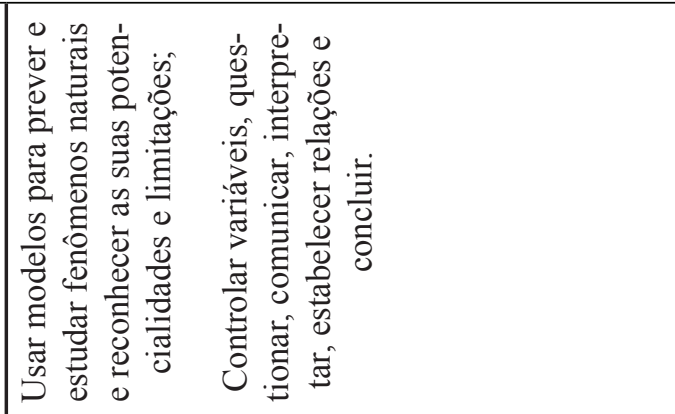 & 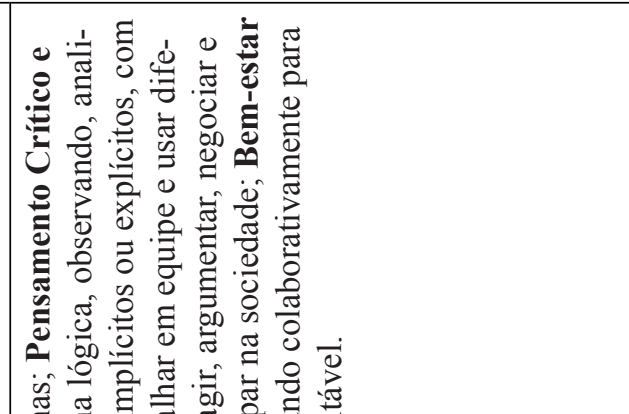 \\
\hline 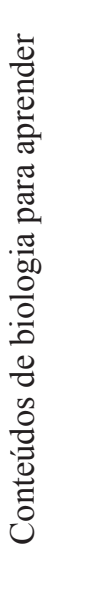 & 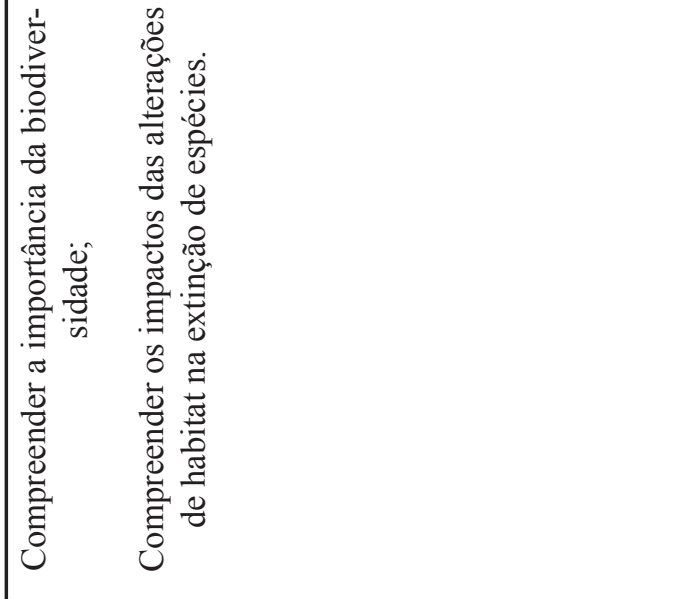 & 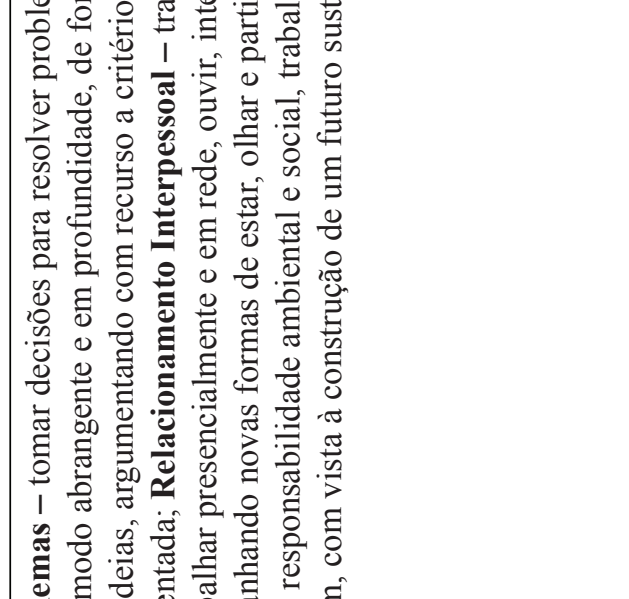 \\
\hline & 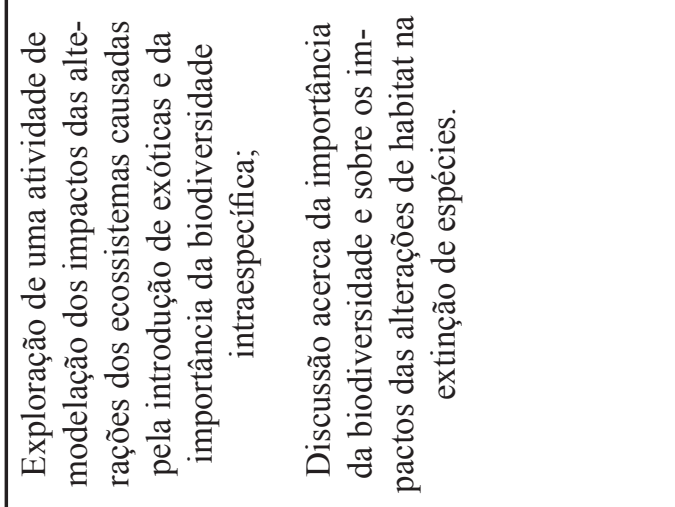 & 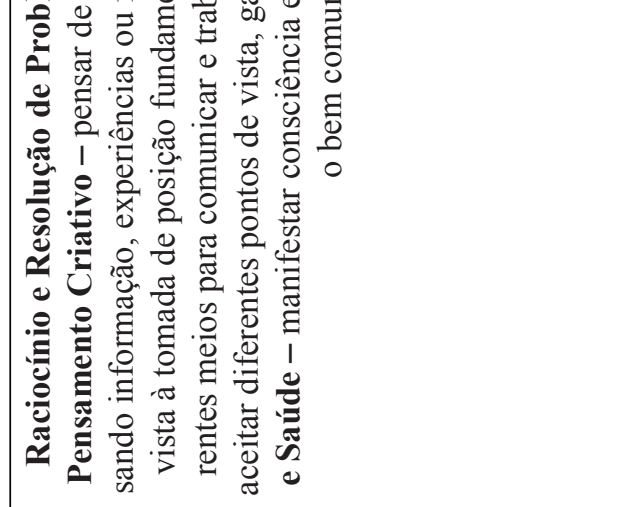 \\
\hline 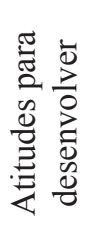 & 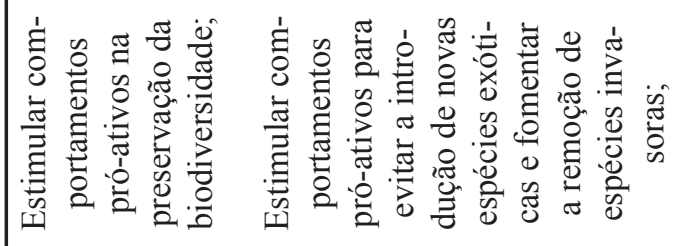 & 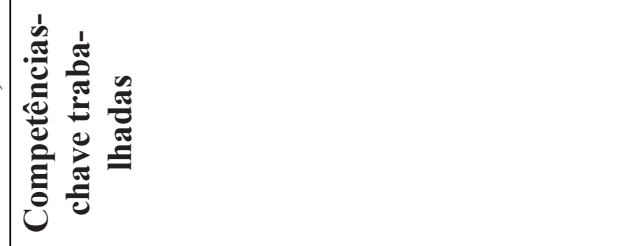 \\
\hline$\frac{\sqrt{0}}{\frac{\tilde{d}}{\tilde{g}}}$ & \multicolumn{2}{|c|}{ 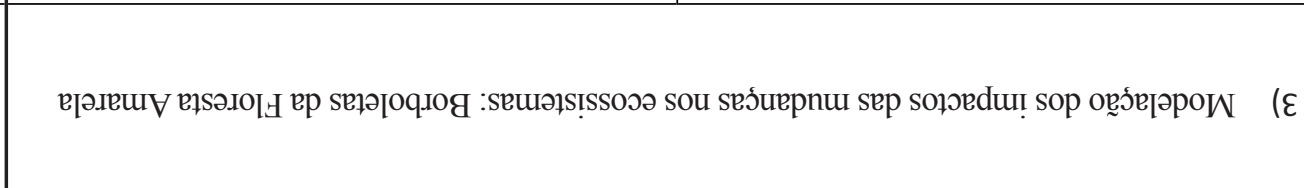 } \\
\hline
\end{tabular}




\begin{tabular}{|c|c|c|}
\hline 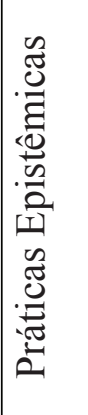 & 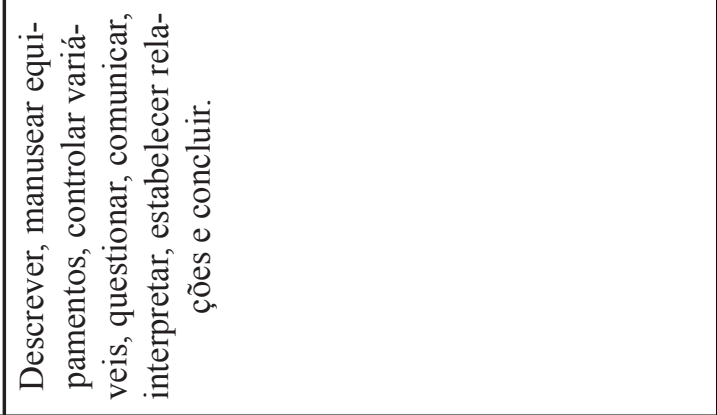 & 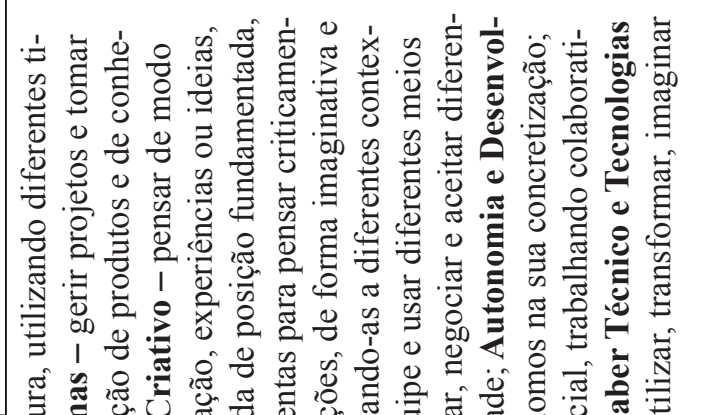 \\
\hline 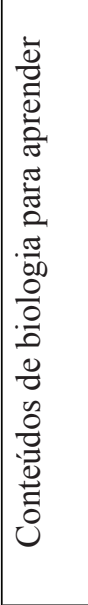 & 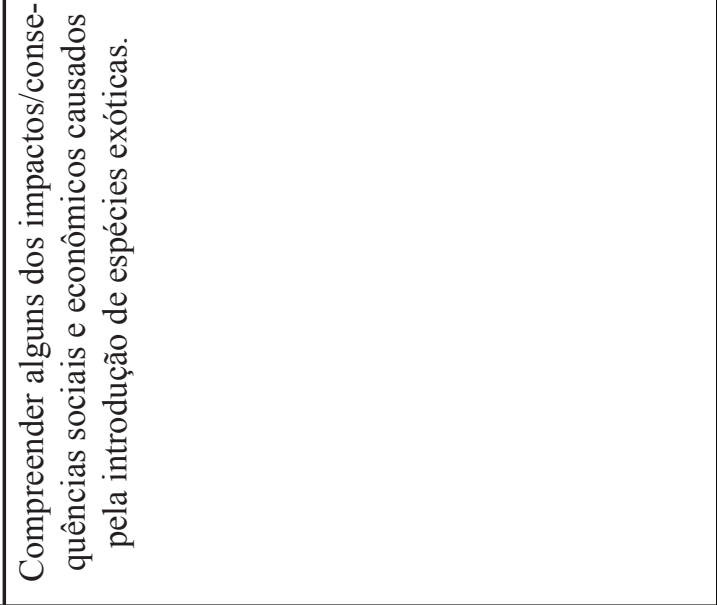 & 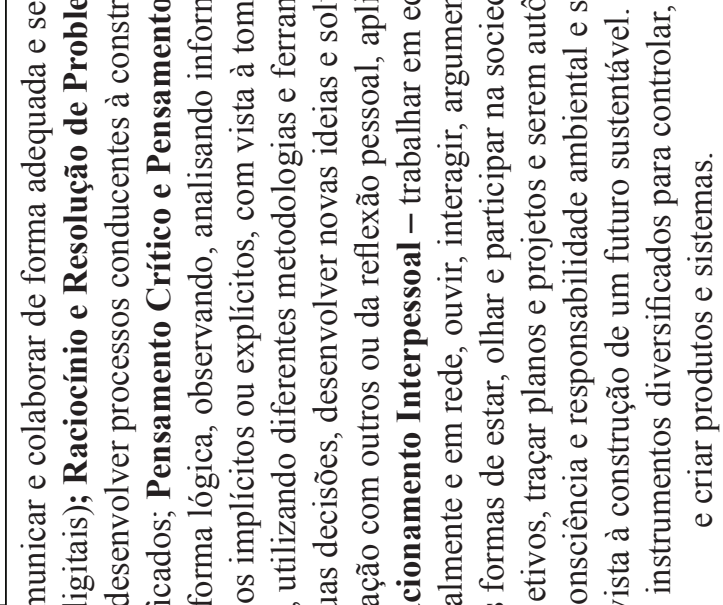 \\
\hline & 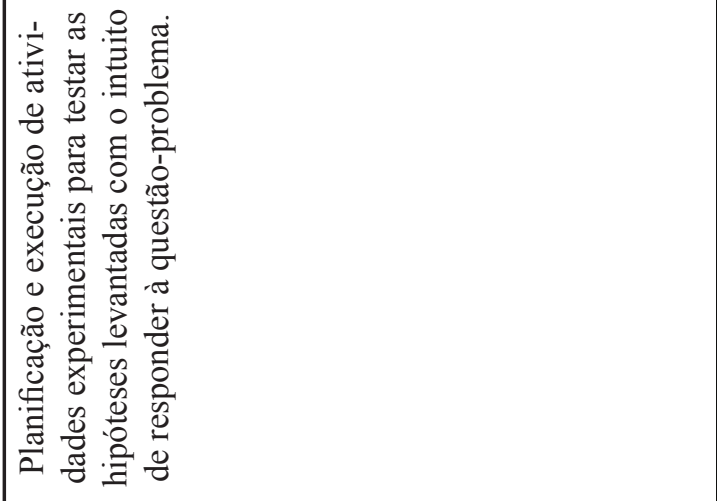 & 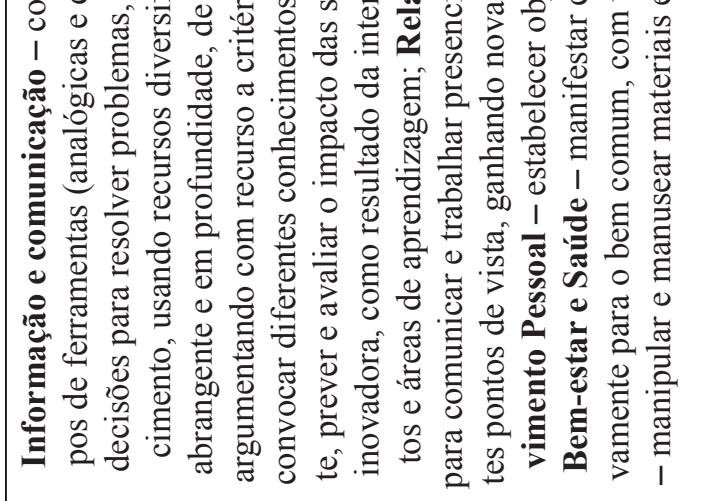 \\
\hline 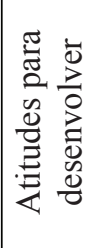 & 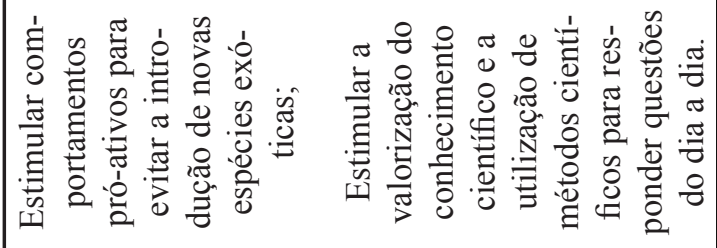 & 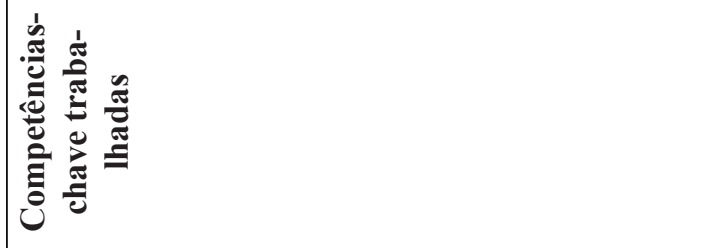 \\
\hline 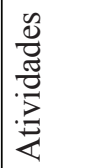 & \multicolumn{2}{|c|}{ 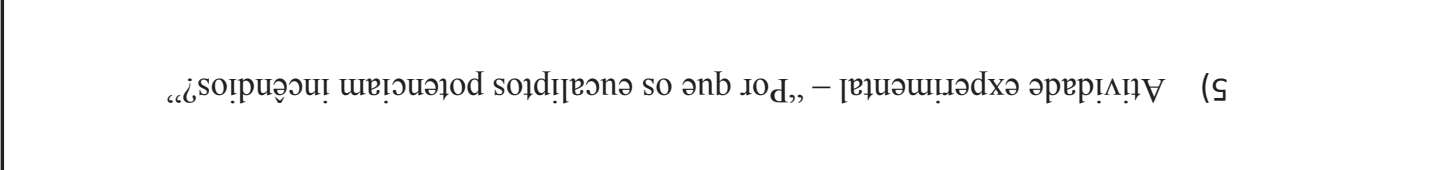 } \\
\hline
\end{tabular}

232 Comunicações | Piracicaba | v. 26 | n. 2 | p. 213-242 | maio-ago. 2019 


\begin{tabular}{|c|c|c|}
\hline 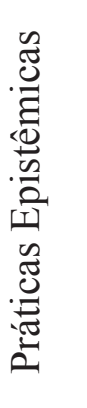 & 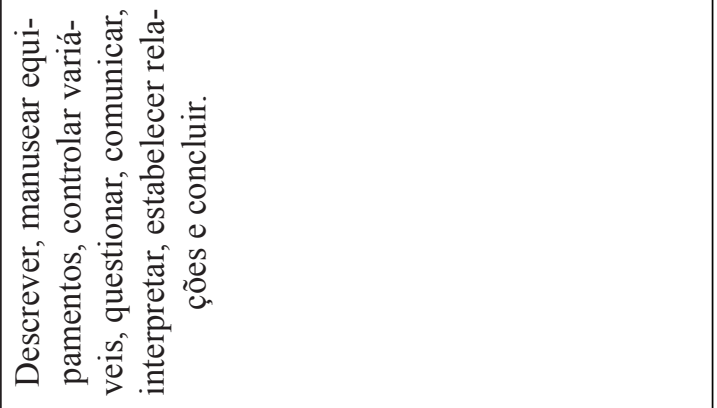 & 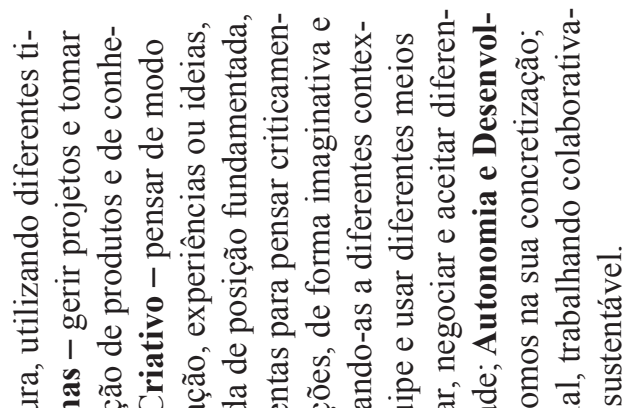 \\
\hline 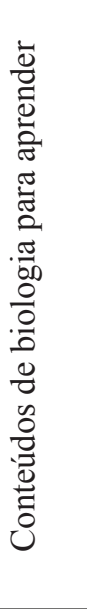 & 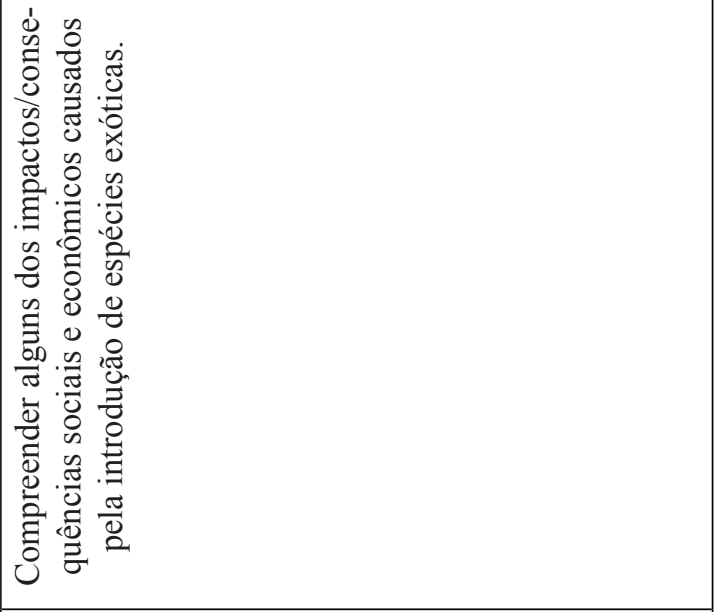 & 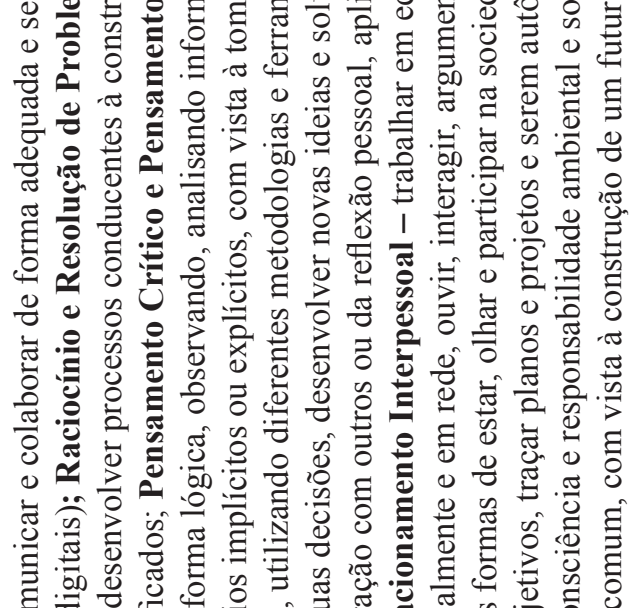 \\
\hline 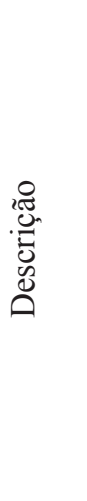 & 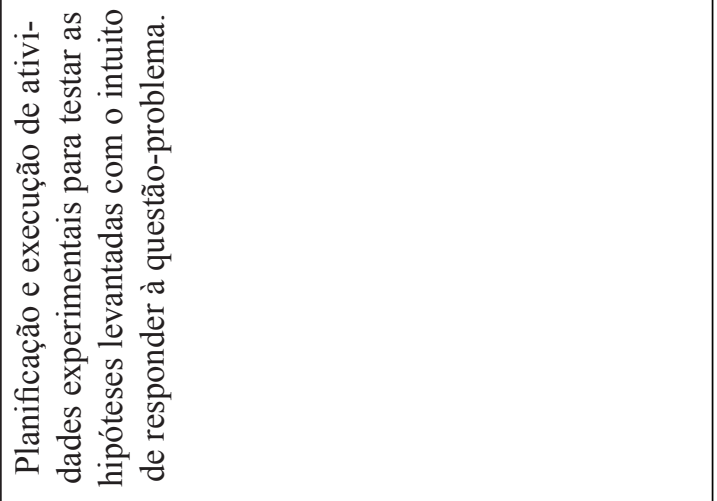 & 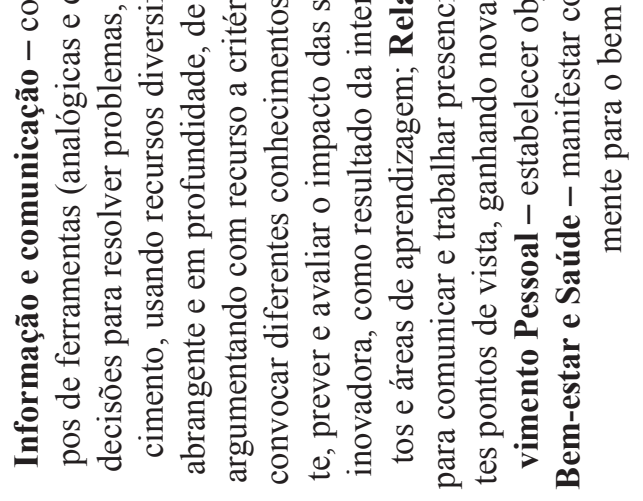 \\
\hline 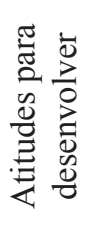 & 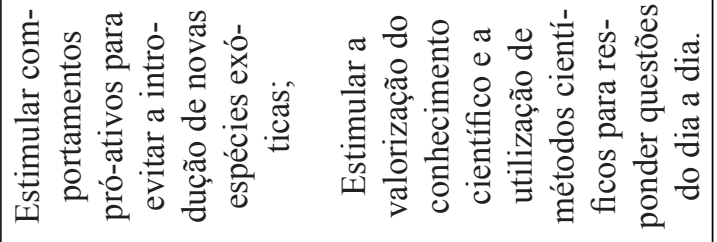 & 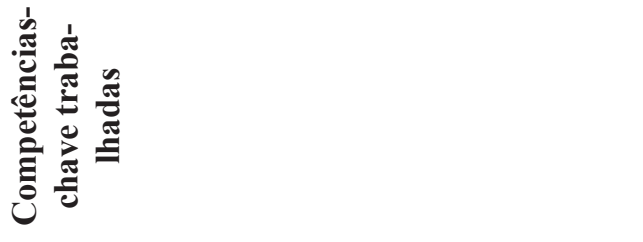 \\
\hline 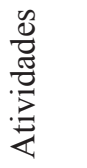 & \multicolumn{2}{|c|}{ 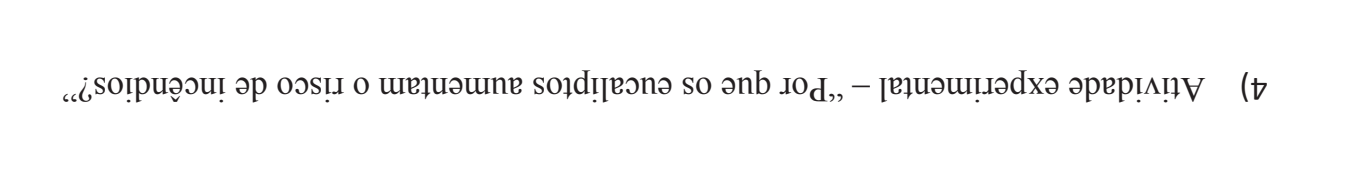 } \\
\hline
\end{tabular}


Anexo II - Carta de Planificação

\section{CARTA DE PLANIFICAÇÃO}

Goldsworthy, A., Feasey, R. (1997). Making Sense of Primary Science Investigations. Hatfield: ASE.

Questão-problema:

ANTES DA EXPERIMENTAÇÃO

O que vamos manter...

O que vamos mudar...

Como vamos registrar os dados

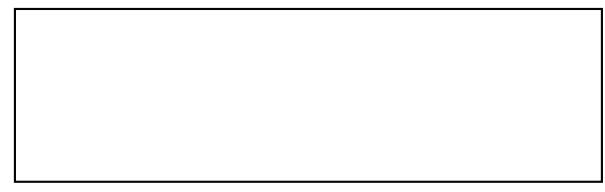

O que vamos medir...
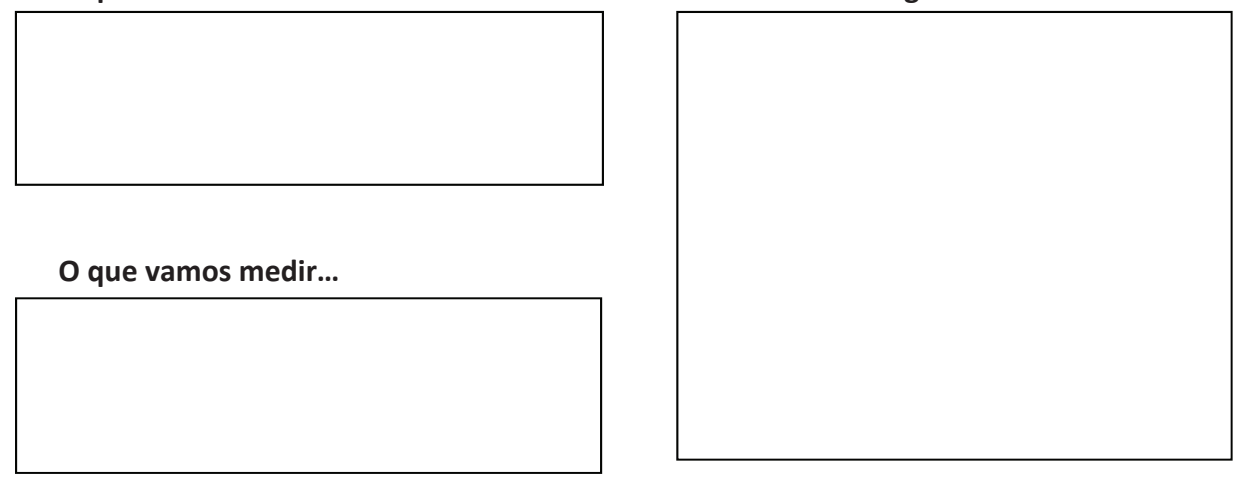

O que vamos fazer...

Do que precisamos...

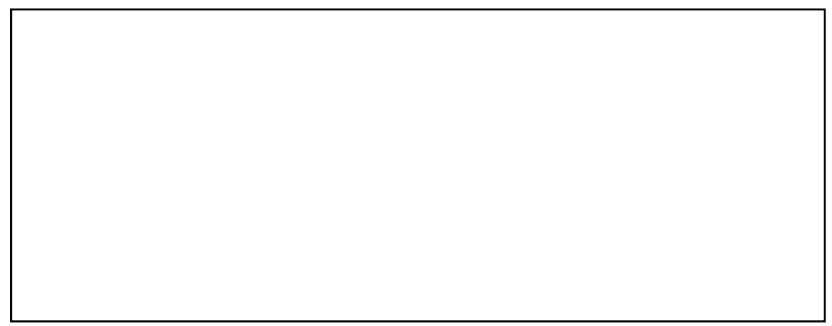

O que acho que vai acontecer e por quê...

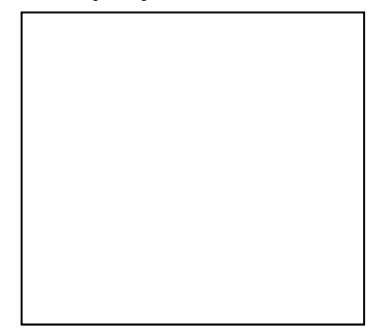

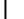

234 Comunicações | Piracicaba | v. 26 | n. 2 | p. 213-242 | maio-ago. 2019 


\section{EXPERIMENTAÇÃO}

$\checkmark$ Executar a planificação seguindo as ideias já definidas

$\checkmark$ Recolher os dados

APÓS A EXPERIMENTAÇÃO

Verificamos aue

Resposta à questão-problema e conclusão...

Data:

Anexo III - Teste (ver teste disPonível em: https://goo.gl/Xs4mNe) 
Anexo IV - Definição dos critérios avaliados em cada pergunta e exemplos das respostas atribuídas a cada critério. Pinta, Boina e Risca são os nomes das espécies fictícias apresentadas aos alunos no teste.

\begin{tabular}{|c|c|c|c|}
\hline Questão 1 & Critério & Definição & Exemplos \\
\hline \multirow[t]{2}{*}{ Previsões } & Pinta & $\begin{array}{l}\text { O aluno indica que é a es- } \\
\text { pécie pinta que terá mais } \\
\text { indivíduos, ou que o quintal } \\
\text { onde essa espécie está plan- } \\
\text { tada terá mais plantas }\end{array}$ & $\begin{array}{l}\text { Aluno } 1 \mathrm{CS} \text {, pré-teste: A do Antônio porque } \\
\text { ia demorar } 2 \text { anos. } \\
\text { Aluno } 5 \mathrm{AG} \text {, pré-teste: Ao fim de } 5 \text { anos o } \\
\text { quintal que tem mais plantas foi o do An- } \\
\text { tônio porque o vento não leva as sementes } \\
\text { para muito longe. }\end{array}$ \\
\hline & Boina & $\begin{array}{l}\text { O aluno indica que é a es- } \\
\text { pécie boina que terá mais } \\
\text { indivíduos, ou que o quintal } \\
\text { onde essa espécie está plan- } \\
\text { tada terá mais plantas }\end{array}$ & $\begin{array}{l}\text { Aluno 19CS, pós-teste: Vai ser o Tomás, } \\
\text { porque germina mais por ano.//I } \\
\text { Aluno 18AG, pré-teste: É o quintal do } \\
\text { Tomás, porque a Boina dá } 5 \text { sementes por } \\
\text { ano. }\end{array}$ \\
\hline \multirow[t]{3}{*}{ Justificações } & $\begin{array}{l}\text { Germina- } \\
\text { ção }\end{array}$ & $\begin{array}{l}\text { Correta se o aluno referir } \\
\text { que o quintal com mais } \\
\text { plantas é o da planta com } \\
\text { maior capacidade de germi- } \\
\text { nação (boina). Ou quando } \\
\text { compreende de forma errada } \\
\text { a indicação da capacidade } \\
\text { de germinação, mas dentro } \\
\text { da sua compreensão indica } \\
\text { a planta com maior capa- } \\
\text { cidade de germinação (ex.: } \\
\text { compreende que germina de } \\
\text { x em x anos) }\end{array}$ & $\begin{array}{l}\text { Aluno } 11 \mathrm{AG} \text {, pós-teste: Ao fim de } 5 \text { anos o } \\
\text { quintal que tem mais plantas vai ser o do } \\
\text { Tomás porque a Boina dá } 5 \text { sementes. } \\
\text { Aluno } 12 \mathrm{CS} \text {, pós-teste: O quintal do To- } \\
\text { más, porque a Boina germina } 5 \text { sementes } \\
\text { por ano enquanto a Pinta só germina } 3 \\
\text { sementes por ano. }\end{array}$ \\
\hline & Dispersão & $\begin{array}{l}\text { Correta se o aluno justificar } \\
\text { a existência de mais plantas } \\
\text { num dos quintais através da } \\
\text { capacidade de dispersão das } \\
\text { sementes }\end{array}$ & $\begin{array}{l}\text { Aluno } 20 \mathrm{CS} \text {, pré-teste: O do Antônio, por- } \\
\text { que é resistente a incêndios e porque se } \\
\text { houver vento vai menos longe. } \\
\text { Aluno } 15 \mathrm{AG} \text {, pós-teste: É o do Antônio } \\
\text { porque a Boina vai muito longe. }\end{array}$ \\
\hline & $\begin{array}{l}\text { Resistência } \\
\text { a Incêndios }\end{array}$ & $\begin{array}{l}\text { Correta se o aluno justificar } \\
\text { a existência de mais plantas } \\
\text { num dos quintais através da } \\
\text { resistência a incêndios (já } \\
\text { previu a existência de incên- } \\
\text { dios) }\end{array}$ & $\begin{array}{l}\text { Aluno 10CS, pré-teste: Eu acho que foi o } \\
\text { do Antônio. Porque se a casa se incendiar } \\
\text { a flor não queima. } \\
\text { Aluno 4CS, pós-teste: Se houver incêndios } \\
\text { o do António porque são sementes resisten- } \\
\text { tes a incêndios. Se não houver incêndios a } \\
\text { do Tomás porque germina } 5 \text { sementes por } \\
\text { ano. }\end{array}$ \\
\hline
\end{tabular}




\begin{tabular}{|c|c|c|c|}
\hline Questão 2 & Critério & Definição & Exemplos \\
\hline \multirow[t]{3}{*}{ Previsões } & Pinta & $\begin{array}{l}\text { O aluno indica que é a es- } \\
\text { pécie pinta que terá mais } \\
\text { probabilidade de aparecer no } \\
\text { quintal do vizinho }\end{array}$ & $\begin{array}{l}\text { Aluno 6AG, pré-teste: Foi a Pinta porque } \\
\text { a semente dele voa pouco e conseguiu ir } \\
\text { para o quintal do Luís. } \\
\text { Aluno 4AG, pós-teste: A planta que eu } \\
\text { acho que foi é a Pinta porque leva as se- } \\
\text { mentes para longe. }\end{array}$ \\
\hline & Boina & $\begin{array}{l}\text { O aluno indica que é a es- } \\
\text { pécie boina que terá mais } \\
\text { probabilidade de aparecer no } \\
\text { quintal do vizinho }\end{array}$ & $\begin{array}{l}\text { Aluno 4CS, pós-teste: Eu acho que é a do } \\
\text { Tomás porque o Tomás vai plantar a Boina } \\
\text { e planta mais longe. } \\
\text { Aluno } 10 \mathrm{AG} \text {, pós-teste: Eu acho que é a } \\
\text { Boina. }\end{array}$ \\
\hline & Risca & $\begin{array}{l}\text { O aluno indica que é a es- } \\
\text { pécie risca que terá mais } \\
\text { probabilidade de aparecer no } \\
\text { quintal do vizinho }\end{array}$ & $\begin{array}{l}\text { Aluno } 21 \mathrm{CS} \text {, pós-teste: Foi a Risca porque } \\
\text { ninguém plantava. }\end{array}$ \\
\hline \multirow[t]{3}{*}{ Justificações } & Germinação & $\begin{array}{l}\text { Correta se o aluno indicar a } \\
\text { capacidade de germinação } \\
\text { como uma maior probabili- } \\
\text { dade de dispersão }\end{array}$ & $\begin{array}{l}\text { Aluno } 13 \mathrm{AG} \text {, pré-teste: Eu acho que foi a } \\
\text { Boina porque a Boina germina de } 5 \text { em } 5 \\
\text { anos. } \\
\text { Aluno } 16 \mathrm{CS} \text {, pós-teste: Eu acho que foi a } \\
\text { do Tomás porque tem } 5 \text { sementes. }\end{array}$ \\
\hline & Dispersão & $\begin{array}{l}\text { Correta se o aluno justificar } \\
\text { o aparecimento no quintal do } \\
\text { vizinho através da capacida- } \\
\text { de de dispersão das sementes } \\
\text { da planta. Será considerada } \\
\text { correta quando indica a plan- } \\
\text { ta com maior capacidade de } \\
\text { dispersão (boina), mas tam- } \\
\text { bém quando indica a planta } \\
\text { com uma capacidade de } \\
\text { dispersão intermédia (pinta) } \\
\text { por ter em conta a distância } \\
\text { que se encontra o quintal do } \\
\text { vizinho }\end{array}$ & $\begin{array}{l}\text { Aluno } 20 \mathrm{CS} \text {, pré-teste: Eu acho que foi a } \\
\text { Boina porque ela é levada para longe. } \\
\text { Aluno 7AG, pós-teste: A boina porque a } \\
\text { semente dela voa para muito longe. }\end{array}$ \\
\hline & $\begin{array}{l}\text { Resistência } \\
\text { a Incêndios }\end{array}$ & $\begin{array}{l}\text { Correta se o aluno indicar } \\
\text { que a resistência a incêndios } \\
\text { confere à planta maior pro- } \\
\text { babilidade de germinar e por } \\
\text { conseguinte maior probabili- } \\
\text { dade de dispersão }\end{array}$ & $\begin{array}{l}\text { Aluno } 1 \mathrm{CS} \text {, pré-teste: A pinta porque era } \\
\text { resistente ao fogo. } \\
\text { Aluno } 21 \mathrm{AG} \text {, pré-teste: Eu acho que foi } \\
\text { a pinta porque tem a semente resistente e } \\
\text { cresce mais. }\end{array}$ \\
\hline
\end{tabular}




\begin{tabular}{|c|c|c|c|}
\hline Questão 3 & Critério & Definição & Exemplos \\
\hline \multirow[t]{3}{*}{ Previsões } & Pinta & $\begin{array}{l}\text { O aluno indica que é a espé- } \\
\text { cie pinta que irá permanecer } \\
\text { no quintal por ser resistente } \\
\text { a incêndios. Consideramos } \\
\text { que indica pinta quando } \\
\text { desenha a planta no quintal } \\
\text { em que teve origem }\end{array}$ & $\begin{array}{l}\text { Aluno } 13 \mathrm{CS} \text {, pós-teste: A planta do Antônio } \\
\text { (pinta) ficou direita mas as plantas dos outros } \\
\text { dois colegas está tudo queimado. } \\
\text { Aluno } 3 \mathrm{AG} \text {, pré-teste: Eu acho que o quintal } \\
\text { do Tomás está queimado porque a planta de } \\
\text { lá não resiste aos incêndios e a planta do An- } \\
\text { tônio não está queimada porque as sementes } \\
\text { resistem aos incêndios. }\end{array}$ \\
\hline & Boina & $\begin{array}{l}\text { O aluno indica que será a } \\
\text { planta boina a permanecer } \\
\text { no quintal. Consideramos } \\
\text { que indica boina quando } \\
\text { desenha a planta no quintal } \\
\text { em que teve origem }\end{array}$ & $\begin{array}{l}\text { Aluno 2CS, pré-teste: } 5 \text { no quintal do Tomás } \\
\text { e do Luís e } 3 \text { no do Antônio, porque as se- } \\
\text { mentes podiam ter continuado na terra. } \\
\text { Aluno } 17 \mathrm{CS} \text {, pós-teste: Eu acho que os quin- } \\
\text { tais estão normais porque as duas plantas têm } \\
\text { em comum serem resistentes aos incêndios. }\end{array}$ \\
\hline & Risca & $\begin{array}{l}\text { O aluno indica que será a } \\
\text { planta risca a permanecer } \\
\text { no quintal }\end{array}$ & Sem exemplos. \\
\hline \multirow[t]{3}{*}{$\begin{array}{l}\text { Justifica- } \\
\text { ções }\end{array}$} & Germinação & $\begin{array}{l}\text { Correta se o aluno con- } \\
\text { siderar a capacidade de } \\
\text { germinação das plantas na } \\
\text { sua resposta escrita. Quan- } \\
\text { do distingue por escrito o } \\
\text { número de indivíduos de } \\
\text { plantas diferentes }\end{array}$ & $\begin{array}{l}\text { Aluno 4CS, pré-teste: O quintal do Antônio } \\
\text { ficou com três flores e o do Tomás com ne- } \\
\text { nhuma, porque diz que a pinta germina três } \\
\text { flores por ano e é resistente aos incêndios e a } \\
\text { boina não é resistente aos incêndios. } \\
\text { Aluno } 1 \mathrm{AG} \text {, pós-teste: O Tomás não fica com } \\
\text { nada porque a boina não é resistente ao fogo } \\
\text { e a do Antônio é, e também germina três se- } \\
\text { mentes por ano. }\end{array}$ \\
\hline & Dispersão & $\begin{array}{l}\text { Correta se o aluno con- } \\
\text { siderar na sua resposta a } \\
\text { capacidade de dispersão da } \\
\text { planta resistente a incêndios } \\
\text { através da resposta escrita. } \\
\text { Quando refere por escrito } \\
\text { que uma das plantas irá } \\
\text { aparecer em outro quintal } \\
\text { que não o de origem }\end{array}$ & $\begin{array}{l}\text { Aluno 14AG, pré-teste: Só tinham a pinta nos três } \\
\text { quintais (e desenha uma pinta em cada quintal). } \\
\text { Aluno 19CS, pós-teste: O do Antônio estaria } \\
\text { com sementes plantadas. O do Tomás com- } \\
\text { pletamente queimado e do Luís com algumas } \\
\text { sementes das plantas queimadas (faz legenda } \\
\text { no desenho a indicar a presença de sementes } \\
\text { da pinta no quintal do Luis). }\end{array}$ \\
\hline & $\begin{array}{l}\text { Resistência } \\
\text { a Incêndios }\end{array}$ & $\begin{array}{l}\text { Correta se o aluno referir } \\
\text { que a planta resistente a } \\
\text { incêndios permanece ou } \\
\text { aparece no terreno (pinta). } \\
\text { Quer através da resposta es- } \\
\text { crita ou desenhada, correta } \\
\text { se desenhar apenas a planta } \\
\text { resistente no quintal de ori- } \\
\text { gem e/ou em outro quintal }\end{array}$ & $\begin{array}{l}\text { Aluno 15CS, pré-teste: Eu acho que a flor } \\
\text { pinta ainda está lá. Porque a flor pinta mes- } \\
\text { mo com incêndios ela resiste. O quintal do } \\
\text { Luís estaria todo queimado. O do Tomás } \\
\text { também estava queimado, porque a flor boina } \\
\text { não dura se houver algum incêndio. E o do } \\
\text { Antônio estava queimado mas a flor pinta } \\
\text { ainda estava viva. } \\
\text { Aluno 6AG, pós-teste: As sementes da pinta } \\
\text { sobreviveram por isso ela está boa. }\end{array}$ \\
\hline
\end{tabular}




\begin{tabular}{|c|c|c|c|}
\hline Questão 4 & Critério & Definição & Exemplos \\
\hline \multirow[t]{4}{*}{ Escolha } & Pinta & $\begin{array}{l}\text { O aluno indica a possibilidade } \\
\text { de trazer a planta pinta como } \\
\text { recordação }\end{array}$ & $\begin{array}{l}\text { Aluno } 11 \mathrm{CS} \text {, pré-teste: Eu traria a pinta por- } \\
\text { que era a mais resistente. } \\
\text { Aluno } 15 \mathrm{AG} \text {, pós-teste: Eu acho que deviam } \\
\text { trazer a planta pinta porque é resistente aos } \\
\text { incêndios. }\end{array}$ \\
\hline & Boina & $\begin{array}{l}\text { O aluno indica a possibilidade } \\
\text { de trazer a planta boina como } \\
\text { recordação }\end{array}$ & $\begin{array}{l}\text { Aluno 18CS, pré-teste: Sim, queria uma boina. } \\
\text { Aluno 6CS, pós-teste: O Tomás não deveria } \\
\text { trazer nada e o Antônio devia trazer a boina. }\end{array}$ \\
\hline & Risca & $\begin{array}{l}\text { O aluno indica a possibilidade } \\
\text { de trazer a planta risca como } \\
\text { recordação }\end{array}$ & $\begin{array}{l}\text { Aluno 6AG, pós-teste: Eu aconselharia os } \\
\text { dois trazerem a pinta ou a Risca. } \\
\text { Aluno } 7 \mathrm{CS} \text {, pré-teste: A planta que deveriam } \\
\text { ter trazido era a Risca, porque era mais re- } \\
\text { sistente. }\end{array}$ \\
\hline & Nenhuma & $\begin{array}{l}\text { O aluno indica que não trazia } \\
\text { nenhuma planta }\end{array}$ & $\begin{array}{l}\text { Aluno } 5 \mathrm{AG} \text {, pré-teste: Eu acho que era me- } \\
\text { lhor não trazer nenhuma porque nenhuma é } \\
\text { perfeita. } \\
\text { Aluno } 12 \mathrm{AG} \text {, pós-teste: Teria dito para es- } \\
\text { colher outra recordação porque as plantas } \\
\text { podem ser invasoras. }\end{array}$ \\
\hline \multirow[t]{4}{*}{$\begin{array}{l}\text { Justifica- } \\
\text { ções }\end{array}$} & $\begin{array}{l}\text { Germina- } \\
\text { ção }\end{array}$ & $\begin{array}{l}\text { Correta se o aluno referir que } \\
\text { um maior número de sementes } \\
\text { potencia a capacidade invaso- } \\
\text { ra. Correta se o aluno referir } \\
\text { que escolhe a planta porque } \\
\text { esta se reproduz menos. }\end{array}$ & $\begin{array}{l}\text { Aluno } 14 \mathrm{AG} \text {, pós-teste: Eu pediria a Risca, } \\
\text { porque a risca germina } 2 \text { vezes por ano. }\end{array}$ \\
\hline & Dispersão & $\begin{array}{l}\text { Correta se o aluno referir que a } \\
\text { maior capacidade de dispersão } \\
\text { das sementes pode potenciar a } \\
\text { capacidade invasora. Correta } \\
\text { se o aluno referir que escolhe a } \\
\text { planta porque esta se dispersa } \\
\text { menos. }\end{array}$ & $\begin{array}{l}\text { Aluno } 16 \mathrm{AG} \text {, pós-teste: Eu aconselharia a } \\
\text { risca porque não voa longe. }\end{array}$ \\
\hline & $\begin{array}{l}\text { Resistência } \\
\text { a Incêndios }\end{array}$ & $\begin{array}{l}\text { Correta se o aluno referir que a } \\
\text { resistência a incêndios poten- } \\
\text { cia a capacidade invasora }\end{array}$ & Sem exemplos. \\
\hline & $\begin{array}{l}\text { Perigo de } \\
\text { Exóticas }\end{array}$ & $\begin{array}{l}\text { Correta se o aluno referir uma } \\
\text { preocupação quanto à intro- } \\
\text { dução de novas espécies em } \\
\text { outro habitat }\end{array}$ & $\begin{array}{l}\text { Aluno } 21 \mathrm{CS} \text {, pós-teste: Eu não comprava } \\
\text { porque não é do meu país. } \\
\text { Aluno } 20 \mathrm{AG} \text {, pós-teste: Eu diria para não } \\
\text { trazerem porque podem ser invasoras. }\end{array}$ \\
\hline
\end{tabular}


Anexo V - Gráficos dos Resultados obTidos em CADA QUESTão no PRÉ E PÓS-TESTE.
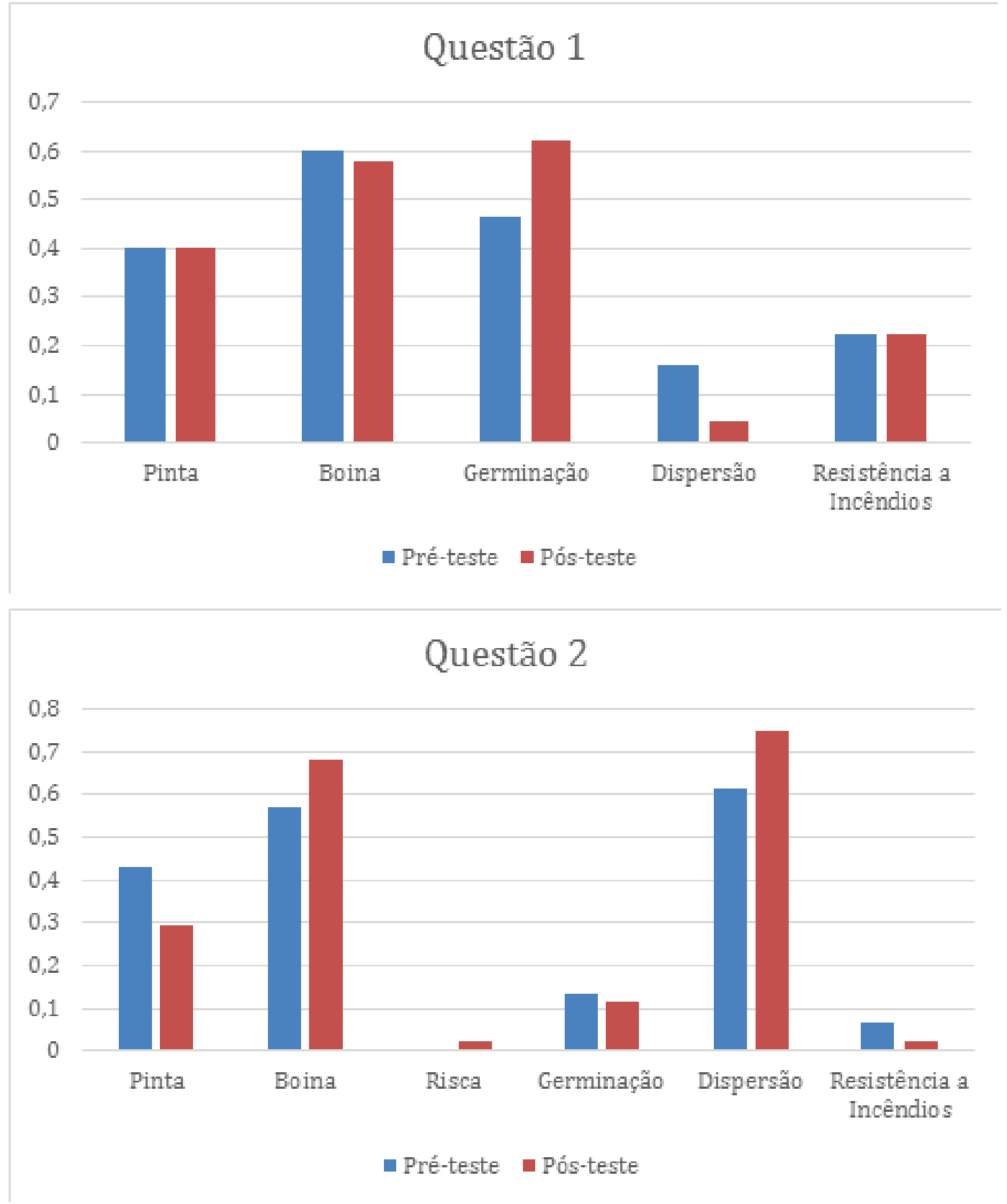


\section{Questão 3}

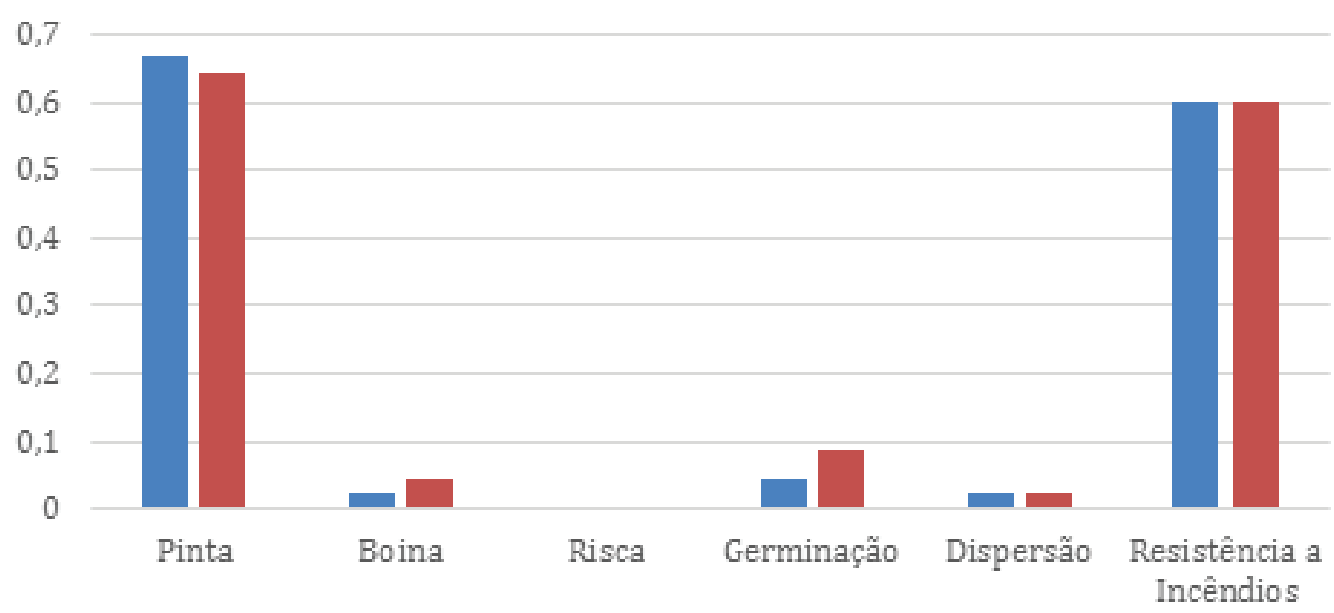

- Pré-teste a Pós-teste

\section{Questão 4}

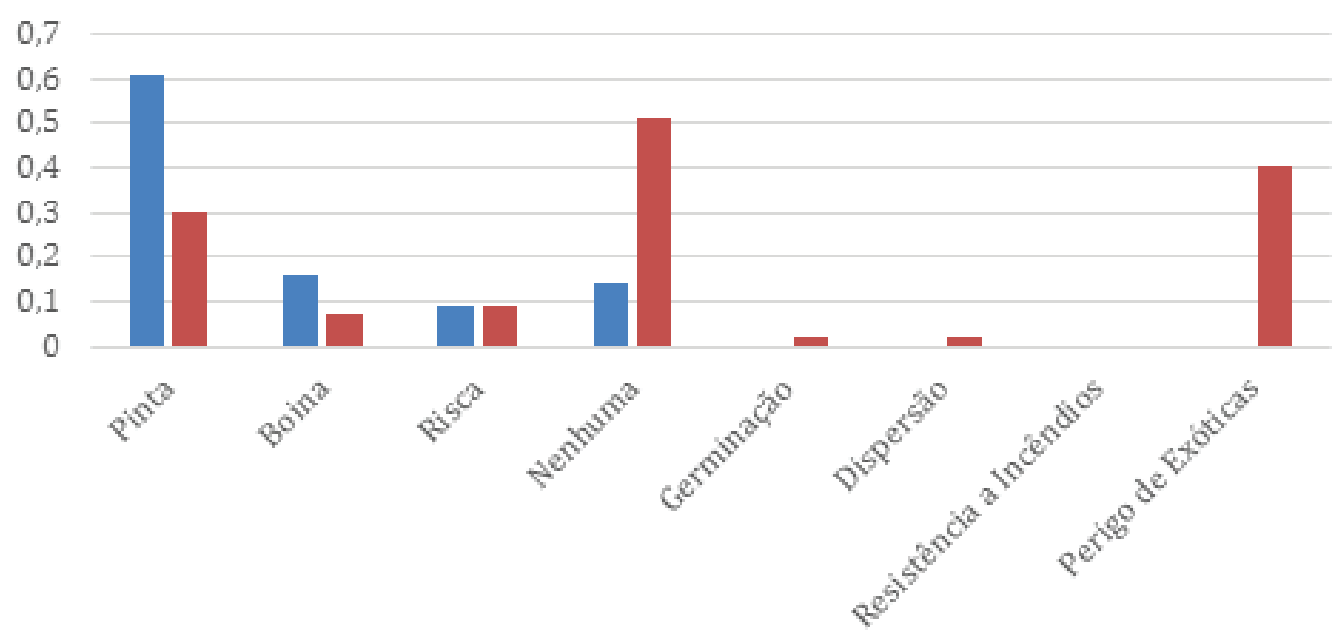

- Pré-teste a Pós-teste 


\section{Patrícia Alexandra Pessoa}

Mestre em Ensino do $1^{\circ}$ Ciclo do Ensino Básico e em Matemática e Ciências Naturais do $2^{\circ}$ Ciclo do Ensino Básico. Escola Superior de Educação do Instituto Politécnico do Porto. Portugal.

\section{Xana Sá-Pinto}

Politécnico do Porto- Escola Superior de Educação, Centro de Investigação em Didática e Tecnologia na Formação de Formadores. Portugal.

\section{Pedro Cardia}

Politécnico do Porto- Escola Superior de Educação. Portugal.

\section{Alexandre Pint}

Politécnico do Porto - Escola Superior de Educação. Portugal.

Submetido em:22-2-2019

Aceito em: 24-9-2019 